\title{
Mechanobiology in the Third Dimension
}

\author{
John A. PEDERSEN ${ }^{1}$ and Melody A. Swartz ${ }^{1,2}$ \\ ${ }^{1}$ Biomedical Engineering Department, Northwestern University, Evanston, IL 60208 and ${ }^{2}$ Integrative Biosciences Institute, \\ École Polytechnique Fédérale de Lausanne (EPFL), Lausanne, Switzerland
}

(Received 11 May 2005; accepted 6 July 2005)

\begin{abstract}
Cells are mechanically coupled to their extracellular environments, which play critical roles in both communicating the state of the mechanical environment to the cell as well as in mediating cellular response to a variety of stimuli. Along with the molecular composition and mechanical properties of the extracellular matrix (ECM), recent work has demonstrated the importance of dimensionality in cell-ECM associations for controlling the sensitive communication between cells and the ECM. Matrix forces are generally transmitted to cells differently when the cells are on two-dimensional (2D) vs. within three-dimensional (3D) matrices, and cells in 3D environments may experience mechan-

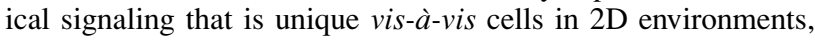
such as the recently described 3D-matrix adhesion assemblies. This review examines how the dimensionality of the extracellular environment can affect in vitro cell mechanobiology, focusing on collagen and fibrin systems.
\end{abstract}

Keywords-Cell mechanics, Tissue mechanics, Collagen, Fibrin, Tissue engineering, Hydrogel, Fibroblast, Stress shielding, Cell strain.

\section{INTRODUCTION}

The development, remodeling, and pathogenesis of tissues such as bone, ${ }^{43}$ tendon, ${ }^{112}$ lung, ${ }^{50,107}$ arteries, ${ }^{49,192}$ cartilage, ${ }^{110}$ breast, ${ }^{19}$ skin ${ }^{101}$ and others all depend in part on mechanical signals. These phenomena also relate to such fundamental processes as stem cell differentiation, in which biomechanical factors can determine lineage fate. ${ }^{3,60}$ As a result of their importance, considerable effort has been expended over the last several decades to define the scope of mechanobiological effects on cells and determine their underlying mechanisms. The study of these processes encompasses several broad research areas including mechanosensing mechanisms, integrin-mediated intracellular signaling pathways, and the mechanics of the cell and its specific cytoskeletal components. In addition, many tools have been developed or modified to explore micromechanical behaviors at the

Address correspondence to Melody A. Swartz, Laboratory for Mechanobiology and Morphogenesis, Integrative Biosciences Institute, Swiss Federal Institute of Technology Lausanne (EPFL), Station 15, 1015 Lausanne, Switzerland. Electronic mail: melody.swartz@epfl.ch single-cell or single-molecule level such as atomic force microscopy, ${ }^{12}$ magnetic $^{208,210}$ and optical ${ }^{74,172}$ bead cytometry, nanopatterned adhesion surfaces, ${ }^{139,191,211}$ micromachined surfaces, ${ }^{48,73}$ particle tracking microrheology ${ }^{198}$ and tissue force culture monitors. ${ }^{53}$

With our evolving knowledge of mechanobiology, an appreciation is emerging for the extent to which the threedimensional (3D) environment of the cell governs the way cells both sense and respond to their in vitro environments, particularly for cells that naturally exist within the 3D interstitial space (e.g. fibroblasts). These cells behave very differently in 3D vs. two-dimensional (2D) environments, not only in terms of their morphology and adhesion (see Fig. 1) but also in their biological response to biophysical factors. The modulation of cellular response is due to many interrelated factors, including how the extracellular matrix (ECM) transmits stress and strain to the cell, how the cell transmits stress to the ECM, and how the two are coupled. Therefore, a continuing challenge to the mechanobiologist is to create relevant, mechanically dynamic $3 \mathrm{D}$ models for the in vitro study of mechanobiology.

This review examines the role of the ECM dimensionality in mediating a cell's response to its biophysical environment, focusing exclusively on in vitro studies of mechanobiology. In Section 2 we discuss the mechanical behavior of commonly used in vitro matrices as compared to those found in native tissue, focusing on the structures of type I collagen and fibrin gels and their differences in behavior in bulk vs. local deformations. We review in Section 3 the major players in cell-matrix coupling, which together with the second section builds a foundation for considering the differences in how cells experience mechanical stress in 3D vs. 2D environments. With this framework, examples of cell behavior in 3D vs. 2D are discussed in Section 4, followed by specific relationships to mechanobiology in Section 5 (cells exerting forces on their ECM) and Section 6 (ECM transmitting forces to cells in 3D). Finally, we end with a short consideration of confocal imaging of cells in $3 \mathrm{D}$ in order to study cell-matrix interactions in the context of 3D mechanobiology. While not exhaustive on any of these individual topics (for these the reader is 

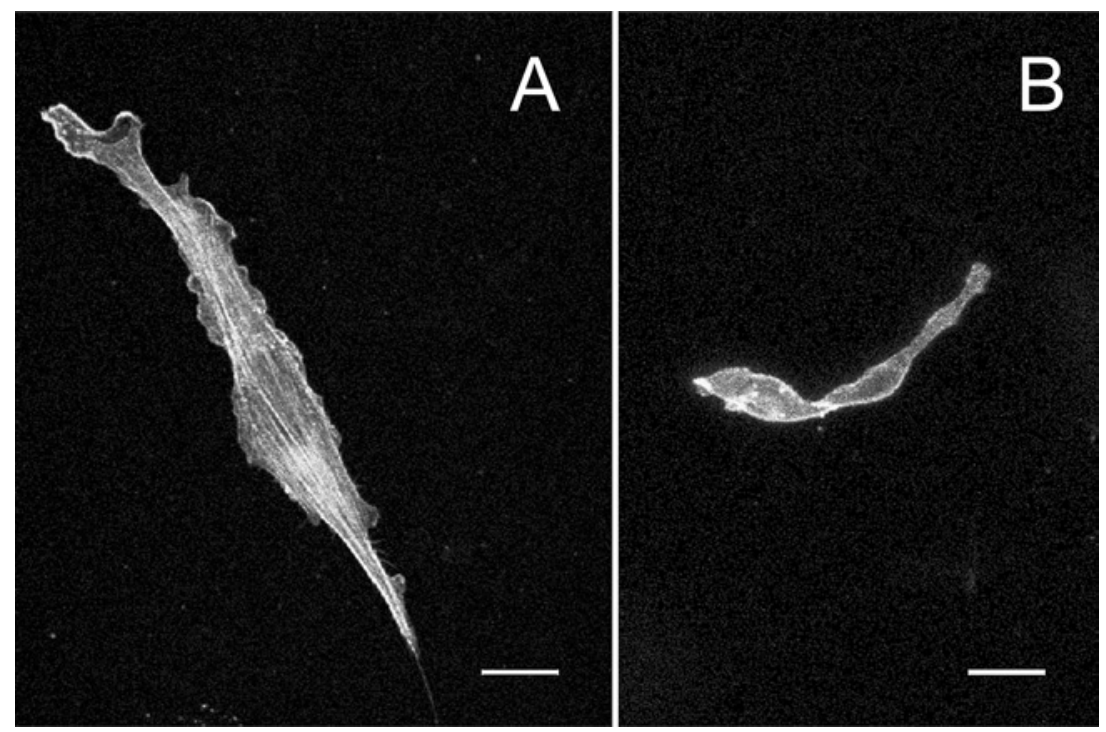

FIGURE 1. Fibroblast morphology on 2D vs. in 3D matrices. 3T3 fibroblasts were transfected with GFP-actin and cultured for $24 \mathrm{~h}$ (A) on collagen-treated glass and (B) within a 3D collagen gel $(2.1 \mathrm{mg} / \mathrm{ml})$. Stress fibers (i.e. polymerized f-actin) are seen more readily in cells grown on $2 \mathrm{D}$ vs. in $3 \mathrm{D}$ gels. Bar $=20 \mu \mathrm{m}$.

referred to excellent reviews and articles on collagen and fibrin gel mechanics, ${ }^{34,35,160,167}$ mechanobiology of various tissues, ${ }^{101,107,110,180}$ general cell mechanics, ${ }^{90,98-100}$ and confocal microscopy techniques ${ }^{184}$ ), this review integrates these themes to evaluate the relevance and importance of dimensionality in mediating cellular responses to the biophysical environment.

\section{PROPERTIES OF IN VITRO MATRICES}

\section{Comparison with Tissue Composition and Function}

The ECM is a tissue-specific, heterogeneous, and complex mixture of various biopolymers and water. In many tissues, type I collagen is the primary structural component of healthy interstitial ECM, with elastin fibers and other types of collagen (out of more than 20$)^{77}$ making up the remainder of the structural (fibrous) components. The huge proteoglycan molecules are also important mechanically because their high fixed charge density imbibes water which regulates hydration and resists compressive forces; ${ }^{110,176}$ they are most abundant in tissues such as the cornea and articular cartilage. Fibronectin is a well characterized cell adhesion substrate; it also binds to other proteins including collagen, heparin, fibrin, and tissue transglutaminase, making it a uniquely important "universal glue" of matrix proteins. ${ }^{150}$ While these proteins contribute to the structural integrity and mechanical properties of the ECM, other matrix proteins instead regulate cell-matrix interactions necessary for cells to evolve and function in a 3D environment. These nonstructural proteins, called matricellular proteins, specifically support various intermediate states of cell adhesion and de-adhesion to help regulate cell motility, proliferation, apoptosis, and differentiation, which are the building blocks of tissue development, tumor formation, and many tissue pathologies. ${ }^{23}$ Thus, in order for cells to utilize their extracellular environment for many complex functions including intercellular signaling, protein storage and transport, growth and remodeling, and mechanical functions, they locally remodel the ECM to create an exquisitely fine-tuned environment in which these functions can be optimized.

Matrices that can orchestrate such complex functions of a natural tissue are not feasible to recreate in vitro. Instead, the main role of most in vitro matrices is simply to provide a substrate with adhesive properties and, in the case of 3D experiments, structural integrity, with the caveat that many cell functions modulated by other ECM proteins will be missing. Thus, simple (single-component) natural or synthetic matrices are typically used that can provide some degree of structural integrity and basic cell adhesion functions; reconstituted type I collagen gels or fibrin gels are among the most common.

\section{Reconstituted Type I Collagen and Fibrin Matrices}

Type I collagen is the most abundant fibrous protein of healthy interstitial tissue (e.g., lung, skin, etc).$^{77}$ Typically purified from rat tail tendon ${ }^{56,57}$ or bovine cartilage $e^{106}$ by acid digestion, collagen forms a gel when returned to neutral $\mathrm{pH}$ in the range of $0.3-30 \mathrm{mg} / \mathrm{ml}$. Reconstituted collagen gels are mechanically weaker and more highly hydrated than natural tissues (see Table 1). These gels are commonly used in many standard in vitro 3D assays such as fibroblast contraction and migration, ${ }^{16,28,115}$ angiogenesis invasion, ${ }^{137,222}$ vasculogenesis, ${ }^{143}$ epithelial 
TABLE 1. Typical values for some in vivo and in vitro matrix properties.

\begin{tabular}{|c|c|c|c|c|c|c|}
\hline & $\begin{array}{l}\text { Reconstituted } \\
\text { collagen gel }\end{array}$ & Skin & $\begin{array}{l}\text { Mammary } \\
\text { carcinoma }\end{array}$ & Liver & Lung & $\begin{array}{l}\text { Reconstituted } \\
\text { fibrin gel }\end{array}$ \\
\hline $\begin{array}{l}\text { Protein } \\
\text { density }(\mathrm{mg} / \mathrm{ml})\end{array}$ & $\begin{array}{l}0.3-30^{160,163} \\
\quad \text { (collagen only) }\end{array}$ & $\begin{array}{l}200-300^{a} \\
\quad \text { (total) }\end{array}$ & $\begin{array}{l}\text { Variable, } \\
\text { but high }\end{array}$ & $\begin{array}{l}9.2 \text { tissue, } \\
\quad 60 \% \text { collagen }{ }^{161}\end{array}$ & $\begin{array}{l}180^{a} \text { (total) } \\
13 \% \text { collagen }{ }^{153}\end{array}$ & $\begin{array}{l}1.5-2.2^{167} \\
\text { (fibrin only) }\end{array}$ \\
\hline Water (\%) & $99^{123,158}$ & $70-80^{4}$ & $50-80^{103}$ & $20^{161}$ & $82^{153}$ & $99^{4}$ \\
\hline $\begin{array}{l}\text { Other ECM } \\
\text { proteins }\end{array}$ & None & $\begin{array}{l}\text { Elastin }(2-4 \%)^{164} \\
\text { PGs }(0.1 \%)^{126,180}\end{array}$ & Variable & Variable & Elastin $(5 \%)^{153}$ & None \\
\hline
\end{tabular}

${ }^{a}$ Computed from percentage of water, assuming total tissue density of $1 \mathrm{~g} / \mathrm{ml}$.

ductal formation, ${ }^{19,147}$ tumor cell ${ }^{72,129,174}$ and macrophage migration, ${ }^{27,59,70}$ and many others. Cells bind to collagen via various integrins that match multiple binding sequences on the surface of the molecule. ${ }^{201}$ Pore size and fiber diameter can be tuned in a modest range by altering the collagen concentration or $\mathrm{pH}$ during gelation, but large changes in $\mathrm{pH}$ are not possible when preparing samples with cells suspended in the soluble collagen solution. ${ }^{160}$ When the solution gels, the individual collagen monomers condense and are crosslinked laterally to form large fibers, but these larger fibers are not crosslinked into a gel-thus they fall into the class of physical gels ${ }^{217}$ because the fibers are merely entangled instead of covalently bound. ${ }^{84,203}$ The ability of collagen fibers to slide and slip with respect to each other will be highlighted later. Collagen gels can be crosslinked via glutaraldehyde ${ }^{148}$ and by glycation, ${ }^{79}$ although glutaraldehyde is toxic to cells (and thus cannot be used when suspending the cells within the gel) and glycation can take weeks. Reconstituted collagen gels, therefore, are mechanically weak but biologically compatible with many cell types, and can serve as an in vitro environment for short-term studies or an initial scaffold that will be remodeled by cells inside for long-term studies.
Fibrin is also commonly used in 3D cultures. As the primary component of a healing wound and a biologically active growth matrix for remodeling and regeneration, it clots into a quick-forming seal that is the body's first response to tissue damage (for a detailed review on fibrin chemistry, see Mosesson et al.). ${ }^{138}$ Thus, it is commonly used for in vitro studies of various types of cell migration, angiogenesis and gel contraction due to its role in wound healing, ${ }^{200}$ thrombosis, ${ }^{183}$ macrophage migration, ${ }^{40}$ and its importance in tumor angiogenesis. ${ }^{52,181}$ It has the advantage that mechanical properties and network architecture are tunable to a greater extent than those of collagen by varying its composition (i.e., relative amounts of fibrinogen, thrombin, and $\left.\mathrm{Ca}^{2+}\right) .{ }^{167,189}$ Furthermore, it forms a useful matrix into which fusion proteins (such as growth factors) can be attached to the matrix via the clotting transglutaminase factor XIIIa. ${ }^{168}$ Cells must proteolytically degrade the dense fibrin mesh by releasing plasmin activators or MMPs (matrix metalloproteinases) in order to successfully migrate $;{ }^{97,117,162}$ thus, fibrin is a useful matrix to study protease-dependent cell migration. The structural architectures of typical in vitro gels made of type I collagen and fibrin as seen by confocal reflectance microscopy are shown in Fig. 2.

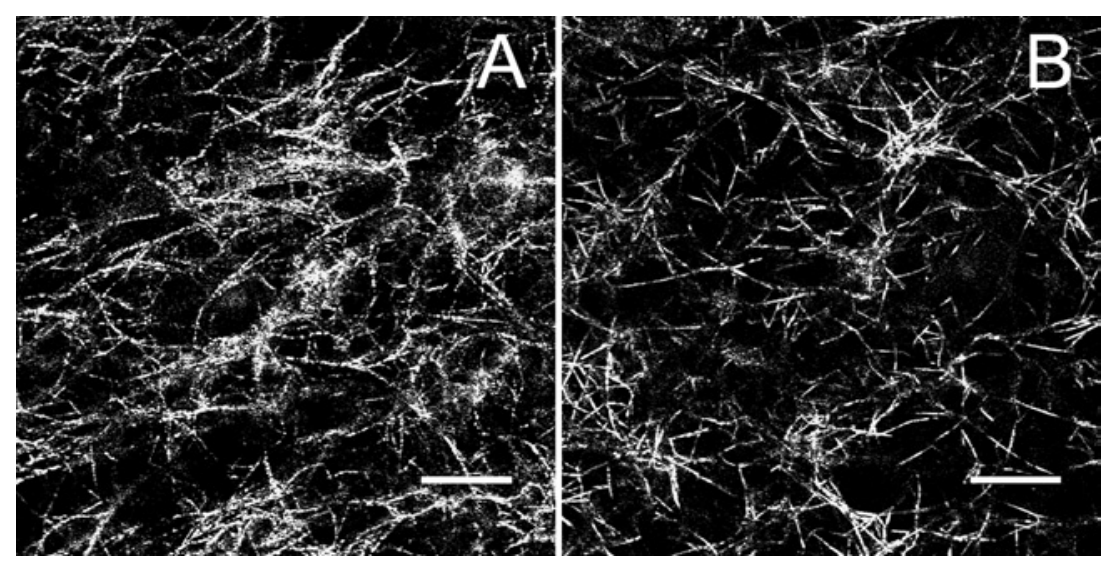

FIGURE 2. Collagen and fibrin gel morphology as seen via confocal reflectance microscopy. Single slice confocal reflectance images of (A) $2.5 \mathrm{mg} / \mathrm{ml}$ collagen gel and (B) fibrin gel with $2.96 \mathrm{mg} / \mathrm{ml}$ fibrinogen. The collagen fibers are on average longer, thicker, and not as straight. Bar $=20 \mu \mathrm{m}$. 
Gels can also be made from elastin, although these are typically used for zymography; ${ }^{8}$ fibronectin, ${ }^{195}$ which is used as a coating for $2 \mathrm{D}$ cell attachment or as a supplement to collagen gels; and hyaluronan, ${ }^{45}$ which is often used in in vitro studies of cell-cartilage interactions. Alginate, a naturally occurring polysaccharide, forms a gel when divalent cations are added to the aqueous sodium alginate solution and is often used to study chondrocyte behavior ${ }^{83}$ since it is minimally adhesive for cells, it often has RGD binding sequences added to create a scaffold with specifically selected adhesion properties. ${ }^{166}$ Other materials have been developed in recent years to specifically control mechanical properties, density, porosity, pore size, adhesion site specificity and density for tissue engineering applications, but the effect of these materials on the mechanobiology of cells embedded within them has not yet been studied in detail. This review is limited to results from experiments with type I collagen and fibrin gels, which are the most commonly used 3D in vitro matrices for studying the mechanobiology of many interstitial cells like fibroblasts.

\section{Matrix Architecture of Collagen and Fibrin}

A surprisingly broad range of values have been reported for fiber diameter and mesh size, which are the two key determinants of matrix architecture in collagen and fibrin gels (see Table 2). Possible reasons for the discrepancies include (1) the methods used to obtain these measurements can introduce artifacts, and (2) the matrix architecture depends on its composition and conditions of gelation (e.g., temperature, $\mathrm{pH}$, ionic strength, etc). Many estimates of fiber diameter and mesh size came from various forms of electron microscopy, which allows for nanometer resolution; however, the fixation and dehydration required for standard electron microscopy techniques can collapse the highly hydrated mesh as well as dehydrate the fibers which can themselves be highly porous. ${ }^{4}$ Electron microscopy

TABLE 2. Typical mechanical properties of simple in vitro matrices.

\begin{tabular}{lcc}
\hline & $\begin{array}{c}\text { Reconstituted } \\
\text { collagen gel }\end{array}$ & $\begin{array}{c}\text { Reconstituted } \\
\text { fibrin gel }\end{array}$ \\
\hline $\begin{array}{l}\text { Fibrous protein } \\
\text { density }(\mathrm{mg} / \mathrm{ml})\end{array}$ & $0.3-30^{160,163}$ & $1.5-2.2^{167}$ \\
Fiber diameter $(\mathrm{nm})$ & $30-300^{216}$ & $4-500^{4}$ \\
& $90-400^{2}$ & $44-150^{167}$ \\
& $200-350^{69}$ & $110-160^{189}$ \\
& $320-800^{24}$ & $110-260^{20}$ \\
Pore diameter $(\mu \mathrm{m})$ & $392-500^{160}$ & \\
& $1-10^{4,118,169}$ & $0.5-11^{189}$ \\
Shear storage modulus $(\mathrm{Pa})$ & $0.15-50^{13,114,118}$ & $0.1-10^{4}$ \\
Shear loss modulus $(\mathrm{Pa})$ & $0.02-8^{13,114,118}$ & $30^{10,29}$ \\
Tensile modulus $(\mathrm{kPa})$ & $1-33^{160}$ & $31-112^{140,165}$ \\
\hline
\end{tabular}

techniques which use quick-frozen samples can yield results similar to those found with confocal microscopic observations of fully hydrated gels, ${ }^{205}$ but the sublimation of frozen water can lead to artifacts from the salt left behind (Mark Johnson, personal communication). Confocal reflection microscopy may over-estimate fiber diameter because light reflecting from the fiber edges suffers from in-plane diffraction artifacts, ${ }^{69}$ and may over-estimate the number of fibers in a given plane due to diffraction along the optical axis of the microscope. ${ }^{109}$ Interfiber spacing or pore diameters of $5 \mu \mathrm{m}$ (see Table 2) may seem large in comparison to cell diameters of approximately $20 \mu \mathrm{m}$, or compared to the fibers shown in Figs. 2 and 3. However, calculating the number of intersections of a $20 \mu \mathrm{m}$ diameter spherical cell with a 3D cubic lattice of fibers spaced $5 \mu \mathrm{m}$ apart yields the surprising result that the sphere will intersect the fibers at approximately 40 places, depending on fiber diameter (unpublished data).

In reconstituted collagen matrices, the fiber diameter and fiber spacing depends on collagen concentration as well as the $\mathrm{pH}$ and ionic strength of the environment in which the gel is forming, ${ }^{220}$ increasing $\mathrm{pH}$ in the range of $6.0-9.0$ decreases the average fiber diameter from 500 to $392 \mathrm{~nm}$, while increasing the collagen concentration increases fiber density but does not significantly affect fiber diameter. ${ }^{160}$ For fibrin matrices, the more complex chemistry of fibrin yields more variables that regulate fiber diameter during clotting, including fibrinogen concentration, thrombin concentration, $\mathrm{CaCl}_{2}$ concentration, the presence of active factor XIII, and ionic strength., ${ }^{467}$ Fiber spacing is not typically reported when fiber diameters are obtained using electron microscopy due to the collapse of the mesh during preparation. However, average fiber spacing in collagen gels has been estimated at between 5 and $10 \mu \mathrm{m}^{169}$ using a density theory developed by Fanti and Glandt, ${ }^{64}$ which is within an order of magnitude of the pore size estimated from diffusion studies. ${ }^{169}$ Saltzman also notes that average fiber spacing in collagen only depends weakly on the concentration of the gel; it decreases as $1 / \sqrt{c}{ }^{169}$ Fibrin gel spacing may also be larger than previously thought; recent confocal measurements that also put average fiber spacing in a fibrin gel at between 5 and $10 \mu \mathrm{m} .{ }^{189}$ Electron microscopy measurements on fibrin clots yielded average fiber spacing of between 0.1 and $0.5 \mu \mathrm{m}$ (calculated from Ryan et al. ${ }^{167}$ ). Clearly, more work is needed to definitively determine the fiber spacing in 3D meshes without preparation artifacts, but recent evidence suggests that the pore size of most reconstituted collagen and fibrin matrices are on the order of several microns.

\section{Bulk Mechanical Properties}

The mechanical properties of fibrous tissues depend on both the strength of the fibers that make up the tissue and the organization and architecture of those fibers. 


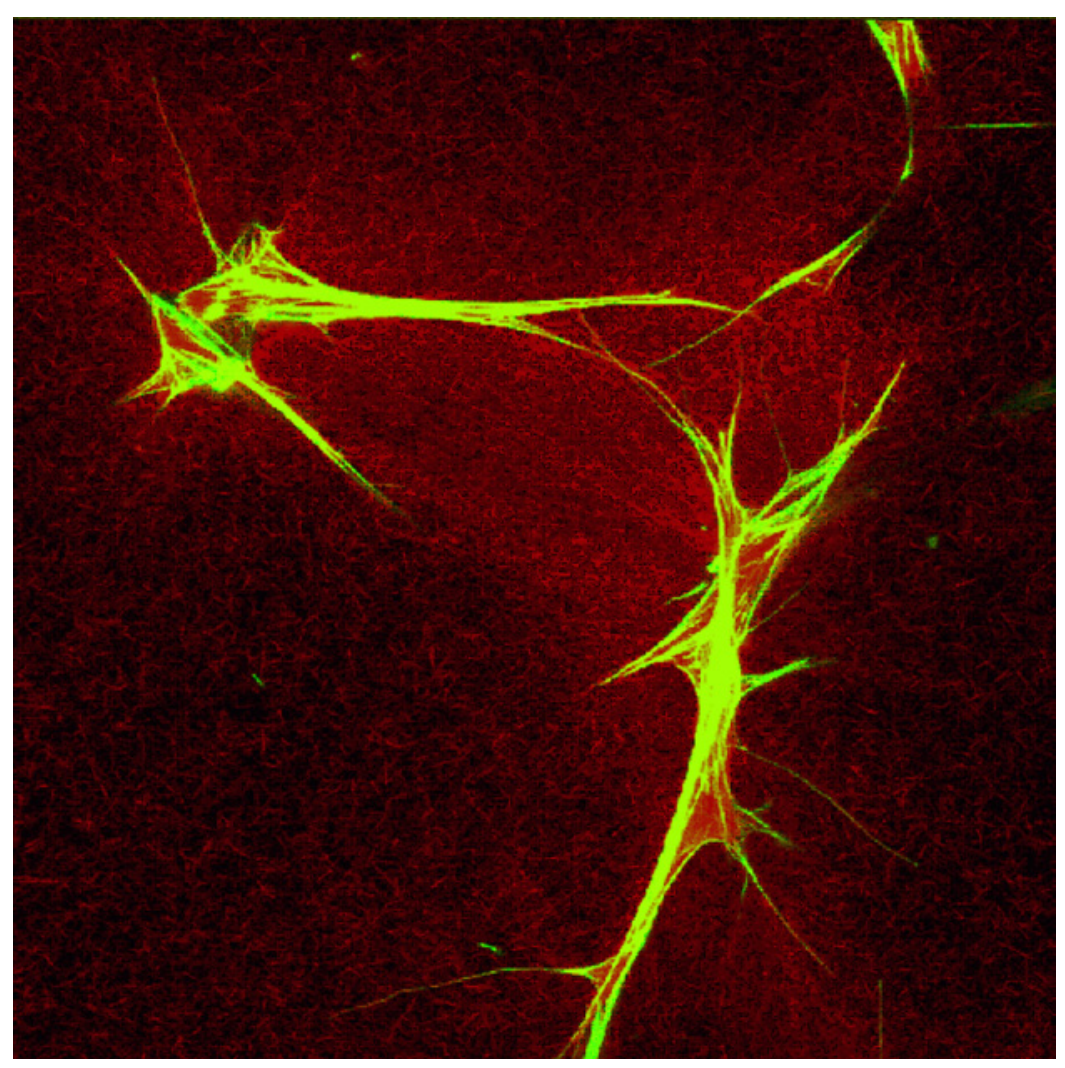

FIGURE 3. Local remodeling of the extracellular matrix near cells. Shown are fibroblasts in a fibrin gel ( $2 \mathrm{mg} / \mathrm{ml}$ fibrinogen); green shows f-actin (phalloidin), red shows the reflectance of the fibrin fibers. Note the close engagement between the f-actin CSK and the ECM fibers, and the higher density of fibers immediately between cells. Image credit: C.P. Ng, Northwestern University.

For many tissues with a dense and well-organized matrix placed under tension, fiber organization governs the low strain response (or "toe region," as the low-modulus portion of the stress-strain curve is commonly named), and when the organizational entropy has been expended from the tissue a higher modulus is seen that reflects the fiber strength (controlled by the enthalpy of the molecular bonds in the fiber) until failure is reached (Fig. 4). In real tissues, fibers are organized to best support physiologic loads and provide specific biomechanical functions. For example, in tendon, collagen fibers are organized in uniaxial bundles parallel to the direction of tension such that the toe region (arising here from the "uncrimping" of the collagen fibers) is quite small and most of the functional range is dependent on fiber strength, ${ }^{203}$ whereas in skin the collagen and elastin fibers are randomly oriented in $2 \mathrm{D}$ to facilitate 2D stretch. ${ }^{180}$

In reconstituted collagen and fibrin matrices, response to mechanical strain primarily arises from water movement and the reorganization of the fiber architecture; thus, their mechanical behavior is mostly entropic as opposed to enthalpic. ${ }^{76}$ Since the solid fraction of fibers is very low in these gels (i.e., they usually consist of $99 \%$ or more water by mass), the bulk mechanical properties are generally in- dependent of the fiber strength (e.g., the gels fail at higher strain than the individual fiber failure strain, but lower stress than the fiber failure stress) because only a fraction of the fibers bear substantial loads even near matrix failure. The fiber density, organization, and crosslink density determine the pore size and porosity of the matrix, and the pores in turn govern the hydraulic conductivity (i.e. relative ease for interstitial fluid movement), which controls the transient response to deformation as water enters or leaves the interstitial space. Compressive loads in hydrogels are initially borne by the fluid phase, and since the fluid volume fraction is so high, the hydraulic conductivity is high resulting in weak resistance to compression.

Under tension, the fibers in the matrices align as organizational entropy is removed and the structure becomes more compact as the fibrous network collapses. ${ }^{206}$ Since reconstituted collagen matrices are much weaker in tension than their individual collagen fibers- $10 \mathrm{kPa} v s .100$ $1000 \mathrm{MPa}^{65,160}$ - the low tensile strength of most collagen gels must be due to fiber rearrangement via bending or sliding. ${ }^{114}$ Quasi-static elasticity tests yield very little appreciable stored energy when samples are loaded in a tensile fashion. ${ }^{148}$ Rheological shear tests can instead be used to obtain the storage and loss moduli $\left(\mathrm{G}^{\prime}\right.$ and $\left.\mathrm{G}^{\prime \prime}\right)$ because 


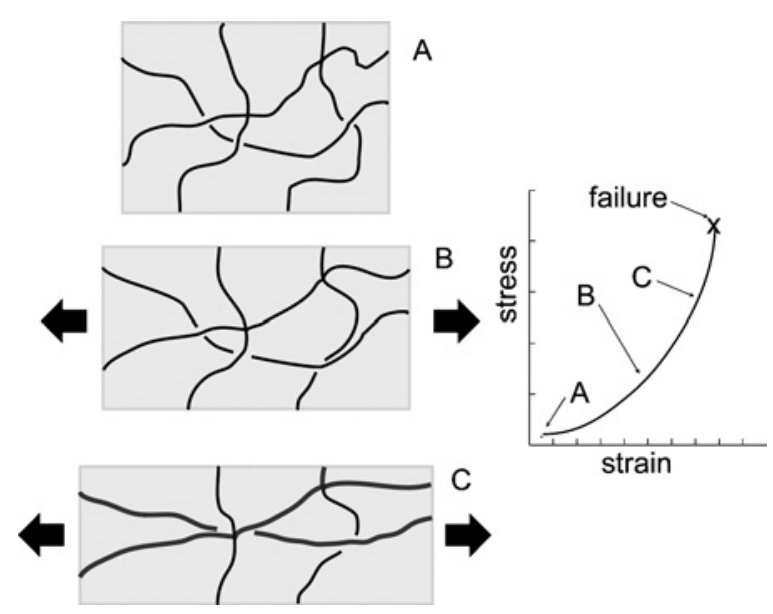

FIGURE 4. Fiber organization regime vs. fiber strength regime in gel deformation. (A) In an unstrained gel, the fibers are relaxed. (B) Initially as the gel is strained, a high compliance behavior is observed as entropy is removed from the system ("toe region"). (C) As the strain continues to increase, load is transferred to the fibers themselves. Some fibers (thick gray) lose entropy as they begin to bear loads via the strength of their intermolecular bonds (enthalpy) until those bonds fail.

of their higher sensitivity, and can even detect the changes in stiffness as a collagen or fibrin gel forms. ${ }^{67,167}$ Under shear loading, the fibers rearrange and do not necessarily come under significant amounts of tension; therefore, they cannot support significant loads. This explains the 1000fold difference between the tensile and shear moduli of a reconstituted collagen gel (Table 2).

Unlike collagen gels, in which fibers are entangled with weak hydrogen bonds, ${ }^{85,171}$ fibrin gels are covalently crosslinked by the transglutaminase factor XIII. ${ }^{138}$ Crosslinking fibers in a hydrogel reduces their entropy, or ability to absorb deflection via fiber rearrangement, by constraining relative fiber movement more than in entangled physical gels. This crosslinking has a major effect on the bulk elastic properties; for example, fibrin gels made with an inhibitor to the crosslinker factor XIII show a three-fold decrease in the storage modulus compared to those made without the inhibitor. ${ }^{167}$

The freedom of movement of the fibers in the gel, and the resulting dissipation of stress, implies that mechanical stresses imposed on 3D gels do not induce uniform strain fields within the matrix, which is described in the next section and which may have important implication for cell response to mechanical stress in 3D vs. 2D environments. Cells plated onto surfaces do not generally experience this difference between local and global stress because most surfaces used in vitro do not have freedom of relative motion. This effect on the local distribution of strain around a cell may be one important reason why dimensionality is a key regulator of cellular response to mechanical input.

\section{Non-Affine Mechanical Behavior}

Many elastic materials we have familiarity with in daily life deform on the microscale in an affine way with the macroscale deformation-that is, the strain is equal on all scales and deformation is continuous throughout the volume. ${ }^{152}$ However, as introduced earlier, fibrous matrices with low fiber volume fraction and crosslink density such as those used as in vitro scaffolds can act quite differently. In these materials, the freedom for fibers to bend, buckle and slip when an external mechanical load is applied implies that the strain on any given fiber within that material may not match that of the bulk matrix due to the resulting dissipation of stress; the local and bulk deflections will be non-affine, and the strains will not be equal in all locations (Fig. 5). ${ }^{35,76,89}$ The relative contributions of fiber buckling, slippage, and bending to overall stress dissipation depend on the fiber architecture and type of stress applied, although very few examples have been examined in the context of mechanobiology. Fiber slippage has been identified as a possible source of stress dissipation in tissues with bundles of aligned fibers in close contact, ${ }^{133}$ but in random 3D fibrous materials some analyses suggest that slippage will only be important if the fibers are short. ${ }^{39,44}$ Chandran and Barocas show that fiber bending is more likely than fiber slippage at points where two fibers meet in a collagen gel. ${ }^{34}$ Regardless of the mechanism of stress dissipation, the local details of non-affine network deformation for a specific hydrogel are difficult to predict or model theoretically, although a recent computational study has highlighted the importance of matrix microstructure in the
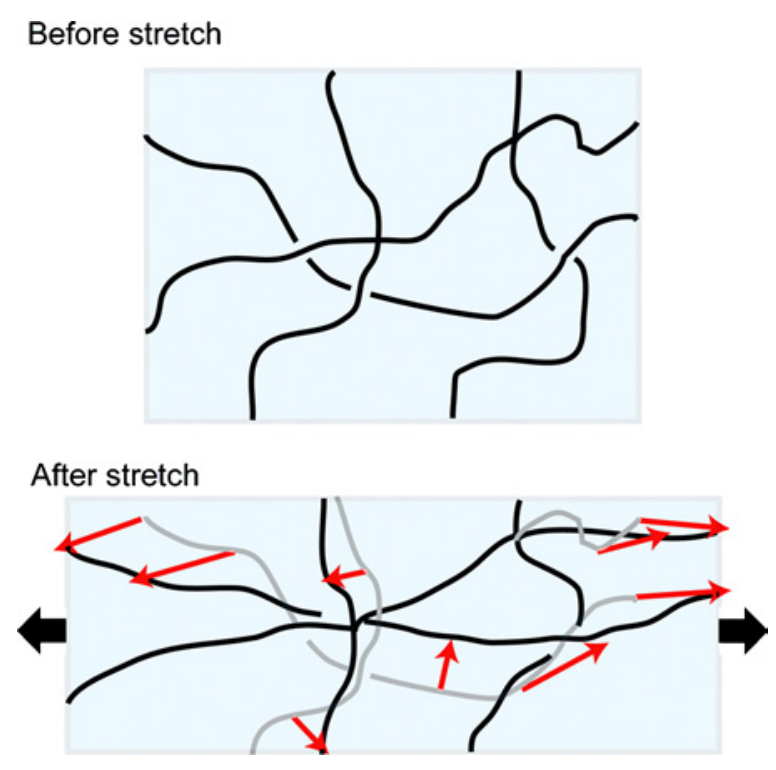

FIGURE 5. Non-affine deformation. Three fibers from "before stretch" are shown (in dark gray) in overlay in the "after stretch" panel. Points on individual fibers are tracked from "before" to "after" stretch using red arrows. 
mechanical response of fibrous gels. ${ }^{1}$ In short, non-affine mechanical behavior of the ECM implies that the information the cell receives about its local environment may not necessarily be correlated to its global environment.

One way to remove mechanical freedom and make a loosely crosslinked matrix more likely to deflect in a bulkaffine fashion is to anchor it to a surface and allow the cells to exert tension on the matrix, thereby decreasing the organizational entropy. Afterwards, when a stress is applied to this matrix (either internally or externally), its mechanical response becomes more bulk-affine in nature. This method, commonly referred to as "pre-stressing" the matrix, is frequently used in studying fibroblast mechanics, ${ }^{28,81}$ although stress is not really stored either by the cells or by the fibers. ${ }^{84}$ Since the local response of pre-stressed gels is more likely to be affine with the bulk response, the mechanical information that the cell gathers about its local environment more closely reflects the global environment.

Another transition between the two regimescontinuum-like deformations in a highly crosslinked gel and non-affine network deformations in a sparsely crosslinked gel-has been recently explored using an actinscruin model by Gardel et al. ${ }^{76}$, which expands on similar findings by Tseng and Wirtz. ${ }^{199}$ Actin polymerizes into fibers that are crosslinked by scruin (an actin-binding protein) in a manner similar to the crosslinking of fibrin by factor XIII. Gardel and colleagues observe two clearly defined types of networks; networks with relatively dense crosslinks that stiffen under strain, and networks with sparse crosslinks that do not stiffen under strain. Furthermore, in the sparse crosslink regime, the elastic modulus depends only weakly on the ratio of crosslinks to fibers, whereas in the regime of strain-stiffening networks, the elastic modulus depends strongly on the crosslink ratio. The sparse crosslink results are interpreted as non-affine network behavior, which exists below a critical crosslink density ratio. These results suggest that a key parameter for determining the response of a network to a mechanical load is the relative density of crosslinks to fibers.

Recent work on the deformation of semiflexible polymer networks has also explored the transition from affine to non-affine deformation as a function of crosslink density and filament rigidity. $\mathrm{Xu}$ et al. showed experimentally, ${ }^{221}$ followed by Head and colleagues computationally, ${ }^{89}$ that non-affine network deformation becomes increasingly affine as the crosslink density increases or as the fibers are made more resistant to bending. Together with Gardel's experimental findings, this demonstrates that the key to non-affine network deformation is the ability of the system of individual fibers to bend, and that non-affine deformation can arise even in the absence of energy-dissipative events (e.g., fiber slippage).

The ability of fibers to bend, and thus yield non-affine network deformation behavior, is typically not duplicated in the $2 \mathrm{D}$ surfaces used for mechanobiology experiments.
Surfaces such as collagen-coated silicone ${ }^{87,95}$ or matrigellaminated polyacrylamide ${ }^{66}$ do not deform in a non-affine fashion, but instead deform in patterns that can be reduced with minimal ambiguity to a smooth vector field; ${ }^{32}$ i.e., they deform as continua. This implies that the detailed information about cell response to mechanical forces gained in these experiments may not necessarily apply to cells embedded in loosely crosslinked gels.

Indeed, one of the major challenges in mechanobiology is to better characterize cell strain $v s$. bulk strain in various 3D systems undergoing mechanical perturbations so that mechanisms of cell response can be better investigated. The actual cytoskeletal strain profile of a cell embedded in a 3D gel relative to that of the bulk gel has not yet been measured. Computational and theoretical methods can give us insight into the mechanisms that result in non-affine deformation within these matrices, but they cannot yet predict the local strain profile of a cell in a given 3D matrix. In summary, non-affine behavior may lead to inhomogeneous strain and, as we shall discuss next, local stress shielding or strain shielding, but this is a nascent area of experimental investigation and is difficult both to model theoretically and explore computationally.

\section{PHYSICAL COUPLING OF CELLS TO THE ECM}

\section{Cytoskeleton-ECM Connections}

Integrins are transmembrane proteins that couple the intracellular and extracellular structural protein networks: they connect the cytoskeleton to the ECM. They are heterodimeric receptors that are specialized in both the extracellular ligands with which they interact as well as the cytoskeletal network components with which they interface intracellularly (for a recent review of integrin biochemistry, see Arnaout et al. ${ }^{5}$ ). They consist of an $\alpha$ subunit and $\beta$ subunit. Eighteen $\alpha$ subunits are known and $8 \beta$ subunits have been identified, but only 24 unique $\alpha \beta$ integrin pairs have been found. The $\beta$ subunit is thought to be the main effector in signaling and binding to cytoplasmic proteins, while the $\alpha$ subunits modulate the binding reactions, perhaps by changing ligand binding efficiency via intermolecular interaction with the cytoplasmic part of the $\beta$ subunit. ${ }^{125,175}$ Specific integrin-substrate interactions depend to varying degrees on the identity of the integrin subunits, the type of binding sites on the substrate or ligand, the presence of various divalent cations, and the integrin activation state, ${ }^{5}$ highlighting the extent to which the cell-matrix coupling can be tuned to accommodate specific matrix conditions. Integrin activation involves binding of proteins on the cytoplasmic side of the membrane, allowing the integrin to act not only as an "outside-in" signaling molecule alerting the cell of attachment, but also as a selectively active cell/ECM anchor that can be modulated by binding of cytoplasmic proteins. Integrins appear to be the first 
element in the signaling cascade that allows detection of external forces (i.e., mechanotransduction), and they have been shown to play key roles in determining cell shape, ${ }^{113}$ levels of cytoskeleton tension, ${ }^{210}$ and other types of cell response to mechanical stimuli. ${ }^{25,36}$

Inside the cell membrane, multi-molecule complexes called cell-matrix adhesions connect the cytoskeleton to the activated integrins and are critically important in transmitting mechanical signals from the ECM (reviewed in Cukierman et al.). ${ }^{46} \mathrm{~A}$ large array of proteins are thought to be a part of focal adhesions under various conditions, and still more molecules apparently interact with adhesion complex proteins to transduce signals or alter function of the cell/ECM coupling, including notably focal adhesion kinase (FAK), the G-protein Rho, and extracellular signal-regulated kinase (ERK) (see Friedl and Bröcker ${ }^{68}$ and Ingber ${ }^{101}$ for reviews). At least four types of cell-matrix adhesions exist that differ in terms of their molecular identities, forces they can exert, and the extracellular substrate required for them to form (reviewed in Cukierman et al.). ${ }^{46}$ The first two types of adhesions, focal contacts (which mature into focal adhesions) and focal adhesions, are perhaps the best known and can exist on single component surfaces. They are capable of transmitting forces from a cell to its substrate in both cell contraction and cell migration, ${ }^{9,124,179}$ and focal adhesions must be maintained in a tensile state to survive. ${ }^{108}$ Fibrillar adhesions require fibronectin, an additional ECM protein and a mechanically compliant substrate, ${ }^{86,108}$ and are thought to be important primarily in the organization and coupling of cell-surface fibronectin to the ECM. Finally, 3D-matrix adhesions were recently described as a unique adhesion requiring a mechanically compliant $3 \mathrm{D}$ substrate as well as fibronectin and an additional ECM protein. ${ }^{47}$ However, little is known about the ability of these adhesions to bear load and their relationship to cell migration.

Most of the existing work characterizing the molecular players in focal adhesions and their capacity for transmitting force has been done on 2D substrates, but currently it appears that focal adhesions in 2D have largely the same features as focal adhesions on single component $3 \mathrm{D}$ matrices ${ }^{47}$ Focal adhesions also require approximately $10 \mathrm{~min}$ to mature and stabilize, ${ }^{15}$ and they appear to undergo aging and growth that may or may not be related to their ability to transmit forces and modulate adhesion. ${ }^{96}$ Balaban et al. found that the amount of force exerted by a fibroblast on an elastic substrate scaled linearly with focal adhesion area $\left(5.5 \mathrm{nN} / \mu \mathrm{m}^{2}\right.$ up to $\left.6 \mu \mathrm{m}^{2}\right)$ as measured by the presence of vinculin. ${ }^{9}$ Other investigators have noted the presence of small focal adhesions, less than $1 \mu \mathrm{m}^{2}$ in area, that can support forces greater than $50 \mathrm{nN} .{ }^{191}$ It seems likely that the fibrillar adhesions and their association with thin actin fibers might have some influence on cell shape and cell motility, whereas focal contacts/adhesions primarily exist to transduce large loads and remodel the matrix.
Locomotive cells often have smaller focal adhesions than cells in a contractile phenotype, and some cells that migrate extremely rapidly have no detectable focal contacts at all. $^{59,70}$

The cytoskeleton to which these various adhesion complexes engage is comprised of three variably active polymer meshes: the actin filament network, the microtubule network, and the intermediate filament network. All three networks exist as polymerized fibers in dynamic equilibrium with monomers or polymerized subcomponents in the cytosol. ${ }^{22,91,142}$ These cytoskeletal networks are biochemically distinct and seem to have different primary functions, but significant cross-talk and interactions exist between them. ${ }^{61,213}$

The actin cytoskeleton has been implicated in cell shape maintenance, ${ }^{36}$ cell migration, ${ }^{151}$ cell force generation, ${ }^{55}$ and mechanotransduction. ${ }^{100,130}$ As the actin cytoskeleton is bound to the ECM via focal adhesions and integrins, it can only react to mechanical inputs delivered along those paths with the possible exception of fluid shear stress. This force may be transduced via membrane fluidity-induced $G$ protein activation or stimulation of actin complexes at the cell membrane. ${ }^{31,49}$ Interestingly, the same non-affine deformation behavior seen with the ECM (Section 2) can also be observed in the cytoskeleton itself. ${ }^{94}$ This implies that cytoskeletal strain is heterogeneous and non-affine, which may introduce a possible mechanism for localizing cytoskeletal remodeling or adhesion reinforcement processes only in the areas they are needed. Because mechanical strain on the cytoskeleton has been shown to alter the binding affinity of paxillin, ${ }^{170}$ a focal adhesion protein, it is possible that the non-affine deformation of the cytoskeleton limits binding of paxillin only to areas near the integrins under strain. In an affine network, stressing one area would result in uniform strain across the network, but observations of cytoskeletal reinforcement in response to mechanical force suggest that the reinforcement is not global, but local. ${ }^{38}$ It is therefore possible that the non-affine network deformation behavior is critical for regulating local cytoskeletal remodeling.

Until recently, the intermediate filament network was thought to be kinetically stable in comparison with the actin cytoskeleton or the microtubules, and its role in cellular mechanobiology appears to be restricted to spatial separation and stabilization of cellular compartments and intercellular contacts like desmosomes. ${ }^{178}$ However, recent work has demonstrated that the intermediate filament network is more dynamic than previously appreciated and appears to be involved in cell migration, although a major role in mechanotransduction or force generation has yet to be found (reviewed in Helfand et al.). ${ }^{91}$ Microtubules are extremely dynamic and active in certain phases of cellular division, and play an important role in generating and maintaining structural polarity in epithelial cells. ${ }^{141}$ Although their role is uncertain, they probably play a 
secondary role in force transduction and maintenance of structures like lamellipodia, ${ }^{7,213}$ and help generate the cell polarity required for migration. ${ }^{61}$ Other cell-specific cytoskeletal networks include the cytokeratin network in epithelial cells, whose role in cell force generation or mechanotransduction is still unclear. ${ }^{149,155}$

\section{Stress and Strain Shielding}

The ECM can shield stress or strain from embedded cells in two ways: it can shield stress by the bulk mechanical properties of the cell-matrix composite, and it can shield strain locally by its non-affine behavior. Stress shielding via bulk mechanical properties refers to the normal sharing of load that occurs in any composite material when one component of that material is weaker than the other. ${ }^{105}$ For example, if cells with an approximate overall shear stiffness of $7.5 \mathrm{~Pa}^{208}$ are embedded in a 3D collagen matrix of shear stiffness $22 \mathrm{~Pa},{ }^{13}$ the matrix will determine the overall shear stiffness of the composite (assuming the cell volume fraction is not too high). For any externally applied stress, the matrix typically bears most of the stress such that the cells are subjected to the same strain as that of the matrix, and since the strain on the cells is reduced, so is the stress they carry-they are "stress shielded" by the stronger bulk material surrounding them. In a well-organized tissue like a tendon, cells are aligned along fibers that are up to seven orders of magnitude stiffer than the cells ${ }^{114,208}$ such that the cell bears almost no load at all. These scenarios depend on the different stiffness of cells and their matrix, but also on homogenous material properties throughout both materials.

The matrix may also shield strain locally by its nonaffine deformation behavior as discussed in Section 2. The degree to which local matrix deformation is non-affine, and the effect this has on a cell embedded within the matrix, depends on the crosslink density of the matrix, the cellmatrix adhesion density and the stiffness of both the cell and fibers. In a matrix with low adhesion site density and small degree of crosslinking, one might speculate that the bulk ECM strain will be greater than that of the cell. This potential non-affine strain coupling is only relevant in 3D systems because of the additional degrees of freedom for relative fiber motion. As mentioned earlier, the actual coupling of cell and ECM strains in such non-affine networks has not been explored, although preliminary observations of a cell undergoing solid shear in a 3D collagen gel support the non-affine arguments (Fig. 6). As entropy is expended with increasing levels of tensile strain, the non-affine case is less likely to occur, as discussed in the previous section. On the other extreme, in a matrix with high adhesion site density and high degree of crosslinking, i.e. a matrix with affine deformation behavior, it is more likely that the cell strain will mimic that of the bulk matrix. Thus, in a loosely crosslinked fibrous matrix, local strain shielding is a function of local fiber organization and the density of mechanical coupling between the cell and the fibers local to it.

Furthermore, the cell can actively control its local mechanical environment by remodeling its local matrix, and can do so in a way that either increases or decreases sensitivity to local mechanical conditions. Increasing local fiber density, either via matrix contraction or collagen fibrillogenesis, and crosslinking surrounding fibers will strengthen the mechanical "cocoon" around a cell (Fig. 3) and shield it from bulk matrix stresses and strains. Alternatively, contracting the matrix into an aligned structure will increase the sensitivity of the cell to global stresses. ${ }^{28}$ The ability of cells to only sense local mechanical events matches their abilities to only alter the local mechanical milieu, but with large numbers of cells acting in concert these local changes can add up to large scale tissue changes. Thus, the spatially complex mechanical system we have described is dynamic. Such matrix remodeling events typically occur within a time frame of hours, ${ }^{82}$ requiring that they be considered in experiments that run for long periods of time.

\section{COMPARISON OF CELL BEHAVIOR IN 3D VERSUS 2D ENVIRONMENTS}

Differences between cells in 3D and 2D environments have been noted in overall morphology, matrix adhesion, manifestation of actin stress fibers, mechanisms of stress generation, cellular migration strategies, gene and protein expression, and response to flow, among others. While the mechanisms underlying these differences remain unclear, some investigators speculate that not only the dimensionality but also the compliance of the matrix are key factors driving the difference in cell response. ${ }^{46}$

\section{Cell Morphology and Adhesion}

Since the early 1970s, investigators have observed morphological differences between fibroblasts sparsely plated on glass and those embedded within 3D collagen matrices, favoring the spindle or stellate shape when in 3D and a spread cell with prominent cellular extensions in $2 \mathrm{D} .{ }^{57}$ In a recent comprehensive study of the effect of matrix composition and dimensionality on cellular adhesion and morphology, Cukierman et al. found that fibroblasts assume different morphologies in relaxed 3D collagen gels and within matrices reconstituted from explanted tissue digests, varying between flattened, spindled, stellate, and dendritic shapes..$^{47}$ Grinnell and co-investigators have noted that only the dendritic phenotype of fibroblasts is expressed in relaxed gels with sparse cell density. ${ }^{190}$ In contrast, cells in high cell density matrices supplied with pro-contractility growth factors move from a dendritic phenotype to a stellate 


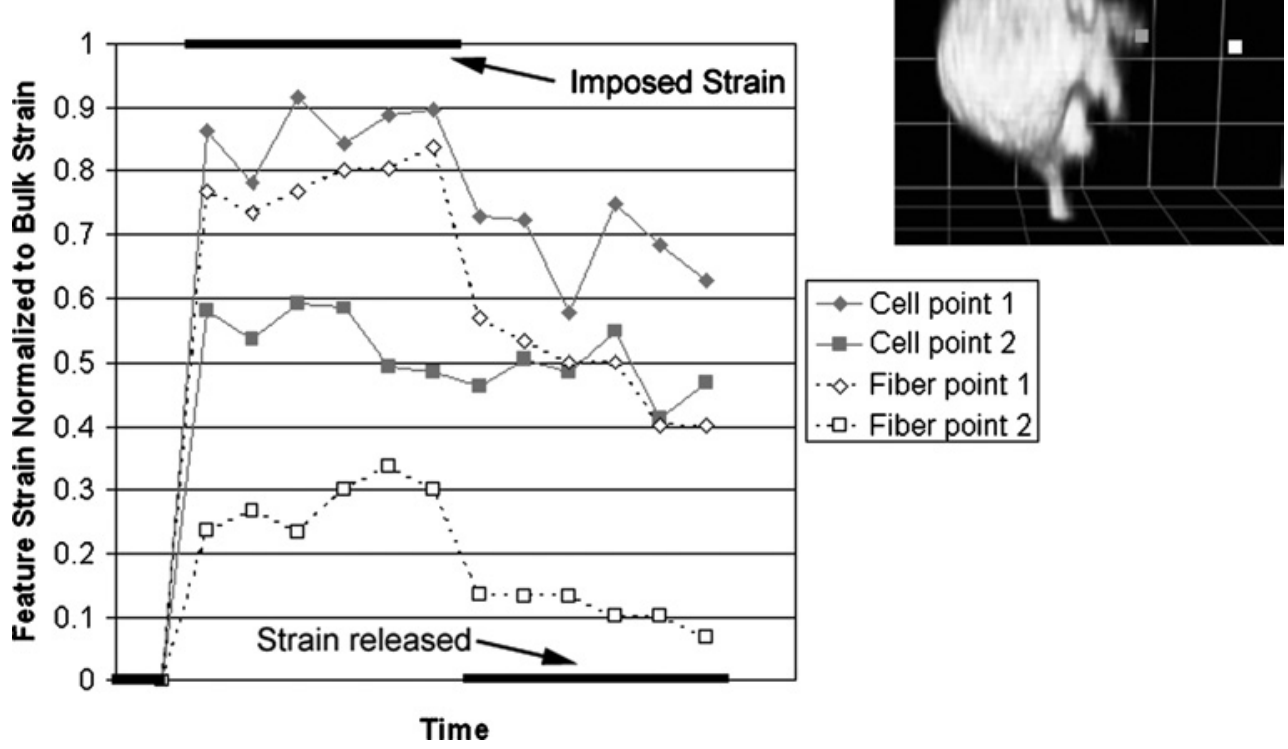

FIGURE 6. Non-affine deformation of a cell in a strained collagen matrix. GFP-actin transfected fibroblasts were placed in a collagen gel and viewed live under confocal microscopy. Points on the cell (gray) and matrix fibers (white) were tracked while a solid shear of $25 \%$ was imposed on the gel using a micromanipulator. Measurements were normalized to the imposed deflection (i.e., the strain that would have existed in an affine system). Spots close to each other on the same cell (see inset) did not move in an affine fashion with the gel or with each other. Moreover, considerable energy (entropy) was lost in the deformation as shown by the lack of elastic recovery after the bulk strain was reversed.

or bipolar morphology within $4 \mathrm{~h}$, as they begin to substantially contract their matrix.

Along with cellular morphology, the type of adhesions generated by fibroblasts also depends on the type and dimensionality of substrate. For example, 3D-matrix adhesions have only been found on cells within mechanically compliant 3D matrices comprised of multiple types of ECM proteins. These 3D-matrix adhesions were much more elongated than focal or fibrillar adhesions from singlecomponent $3 \mathrm{D}$ matrices or $2 \mathrm{D}$ substrates, and were the only adhesions to include paxillin, vinculin, FAK, phosphotyrosine, $\alpha$-actinin, activated $\beta_{1}$ integrin and $\alpha_{5}$ integrin all co-localized. ${ }^{47}$

The mechanism by which the cell senses the dimensionality of its substrate, and thus expresses the appropriate adhesions and morphology, is not clear. One possibility is that the cell can integrate global cues around its entire surface and thereby "sense" the spatial organization of activated adhesions. Another possibility is that the formation of 3D-matrix adhesions requires a molecularly complex substrate with a compliance typically not seen in in vitro 2D surface experiments or in mechanically flattened 3D matrices. In fact, when cell-derived 3D matrices were stiffened by crosslinking with glutaraldehyde, cells plated into that matrix did not form 3D-matrix adhesions but instead formed focal adhesion-like structures, ${ }^{47}$ suggesting that mechanical cues may be the key input that informs the cell of the dimensional status of the matrix.

\section{Fibroblast, Macrophage, and Tumor Cell Migration}

Cell migration is a complex orchestration of events, including cellular shape change, adhesion and de-adhesion to the extracellular substrate, and exertion of force on the substrate via adhesion complexes. Since all of these processes differ in $3 \mathrm{D}$ vs. $2 \mathrm{D}$ environments, it is not surprising that cell migration through 3D matrices differs greatly from that on 2D substrates. In 2D, adhesion is critical for modulating migration via force transmission to the substrate in haptokinetic cell migration. ${ }^{68}$ Briefly, the cell forms adhesions forward of the main cell body, generates traction forces to move the cell body, and then detaches adhesions at the rear of the cell. Other migration mechanisms must exist, however, as some non-adherent cell types fail to migrate on 2D collagen surfaces at all, but are capable of migration inside a $3 \mathrm{D}$ collagen matrix. ${ }^{27}$

An inverse correlation between adhesion strength and migration speed has been shown in numerous 2D studies. For example, in a recent study of fibroblast migration on 2D surfaces, Katz et al. showed that the cells migrated more slowly and formed focal contacts on immobilized fibronectin surfaces, as compared to surfaces with adsorbed, but not covalently linked, fibronectin where fibrillar contacts were used for adhesion. ${ }^{108}$ This study also found that cells plated on immobilized fibronectin formed focal contacts while cells plated on mobile (adsorbed but not covalently linked) fibronectin formed fibrillar contacts. There is some evidence that adhesion strength and cell migration 
speed might have a similar inverse relationship in 3D contexts ${ }^{115}$ as that seen in 2D on fibronectin, ${ }^{108}$ collagencoated polyacrylamide, ${ }^{219}$ and decades ago on glass ${ }^{42}$ surfaces.

In the absence of other cues, cells tend to migrate in the direction in which they are already aligned, a phenomenon called contact guidance. ${ }^{197}$ Therefore, one consequence of mechanical stress aligning the fibers of a gel is that the mechanical force can affect the direction of cell migration within that gel. Contact guidance has already been exploited to direct neurite outgrowth in vitro. ${ }^{51}$ Fibroblasts in particular have long been known to align along aligned collagen fibers, ${ }^{17}$ but the extent to which aligned fibers direct cell process extension and migration, instead of the reverse, is still under investigation. Cells may experience competition between mechanical signals and biochemical ones, as seen in a recent study that place a chemotactic gradient in opposition to a contact guidance field. ${ }^{26}$ In this case, the chemotactic gradient appeared to dominate the cell response, but the fibers of the 3D environment still influenced cell alignment.

In one of the few studies to directly compare 3D and 2D migration rates, Friedl's group showed that on hyaluronic acid (HA)-coated 2D surfaces, MV3 melanoma cells displayed increasing migration rates with increasing concentrations of HA, but showed no dependence of migration rate with HA concentration in 3D collagen matrices. ${ }^{129}$ They suggest that this is likely due to the fact that HA forms a low modulus gel in a 3D hydrated lattice, which contrasts with the stiff-branched strands that bind to a $2 \mathrm{D}$ surface. This difference in the physical conformation of an ECM molecule (HA, in this case) illustrates the subtle but powerful effect dimensionality can have on the physical environment around a cell.

Another recent study showed that non-muscle myosin heavy chain II-B (NMHC II-B) was required for migration and fiber translocation in 3D collagen matrices, but was not required for migration on $2 \mathrm{D}$ surfaces. ${ }^{132}$ In $2 \mathrm{D}$, this molecule could be shown to participate in a "hand-over-hand" lamellipodial mechanism for locally retracting collagen fibers towards the cell. NMHC II-B ${ }^{-/-}$ cells only contracted floating collagen matrices one-third as much as control cells, but gel contraction could be fully restored by transfecting the NMHC II-B ${ }^{-/-}$cells with GFP NMHC II-B. Furthermore, the internal cellular localization of NMHC II-B depended on whether or not the cell was plated into a $3 \mathrm{D}$ matrix or onto a $2 \mathrm{D}$ substrate. These findings further demonstrate that cells on 2D surfaces $v s$. in 3D matrices use different mechanisms for exerting force, even when they both appear to be using a haptokinetic strategy for interacting with their substrate.

Some immune cell types including $\mathrm{T}$ lymphocytes and dendritic cells migrate through 3D collagen matrices without adhesion mediated by $\beta_{1}$ integrin, the primary collagen- binding integrin. ${ }^{72}$ Indeed, although neutrophils can migrate inside 3D collagen gels in an integrin-independent fashion, ${ }^{70}$ they are apparently unable to migrate on $2 \mathrm{D}$ collagen-coated surfaces altogether. ${ }^{27}$ This indicates an amoeboid mode of migration - that is, movement through the formation of pseudopods in matrix pores and subsequent "pulling" of the cell body via cell shape changes through the pore-which is clearly irrelevant for migration on 2D substrates. Even some larger tumor cells that normally use integrin- and protease-dependent migration strategies in 3D gels can continue to migrate via this strategy when MMP and other protease activity is blocked. In a recent study, fibrosarcoma and carcinoma cells were subjected to a protease inhibitor cocktail in an in vitro 3D collagen gel migration model, blocking the normal proteolytic migration strategy of these cells. ${ }^{218}$ However, the cells' migration speed remained essentially unchanged because they switched to a new migration strategy that was marked by a lack of the normal indicators of proteolytic migration. The investigators observed no $\beta_{1}$ integrin clustering, no association between MT1-MMP and $\beta_{1}$ integrin, and a diffuse cortical actin CSK. Similar results were obtained with cells that were pre-treated with the protease inhibitor cocktail and then injected into murine dermal tissue and observed intravitally. ${ }^{218}$ The emergence of this mutability in migration strategy appears to be specific to the 3D environment, since adhesion-independent migration has not been observed to date in $2 \mathrm{D}$ migration studies.

Thus, we see that the haptokinetic cell migration strategy, long considered the primary means of mesenchymal cell locomotion, is not the only means available to cells moving through a 3D matrix. Since the 3D matrix is considerably more compliant than many of the surfaces used to study fibroblast migration to date, more studies of cell migration in 3D are needed to supplement our understanding of adhesion-based 2D cell locomotion. The realm of non-adherent cell migration in 3D matrices is only now emerging, and it raises questions not only about mechanisms for generating the shape changes and internal forces required for this kind of cell migration, but also whether the cells undergoing this type of movement are still able to sense the mechanical state of the matrix, or even whether it is important that they do so.

\section{STRESS GENERATION AND THE ROLE OF SUBSTRATE STIFFNESS IN STRESS FIBER FORMATION}

Fibroblasts and other contractile cells compact collagen gels in both 2D and 3D via force generation during cell migration, called traction, ${ }^{88}$ or via the actin-myosin machinery of the cell, called contraction. ${ }^{131}$ Due to its importance in wound healing and fibrosis, the generation of forces by cells within a matrix was one of the first areas of $3 \mathrm{D}$ cell mechanobiology. Early experiments showed that fibroblasts 
suspended in free-floating collagen compacted the gels to a small fraction of their original size in a cell densitydependent manner. ${ }^{16}$ Further investigation revealed that the fibroblasts were not degrading the matrix significantly but were instead reorganizing existing collagen fibers. ${ }^{84}$ This was shown to be a two-step process whereby the cells rearranged the fibers and then non-covalently stabilized the reorganized state. This process depended on an intact actin cytoskeleton and the ability of the cells to adhere to the collagen fibers, which required serum in the cell media. ${ }^{84}$ However, another study showed that if the cells were anchored and allowed to generate tension in the gel (for at least $24 \mathrm{~h}$ ), then on release the cells could contract the gel more quickly than they had contracted unanchored gels, apparently using actin-myosin machinery. ${ }^{136}$ For a number of years, investigators attempted to reconcile the two modes of fibroblast-mediated gel compaction-traction and contraction-into a single mechanism. However, in recent years it has become clear that the cells are responding in two distinct fashions determined by the local extracellular compliance, ${ }^{6}$ and that these two compaction mechanisms are indeed distinct and, to some extent, independent.

Cells exert forces in an anchored gel using the actinmyosin machinery, which manifests visually as stress fibers. ${ }^{30,120,214}$ Stress fibers are large bundles of polymerized actin filaments heavily crosslinked by $\alpha$-actinin ${ }^{119}$ and often contain $\alpha$-smooth muscle actin ( $\alpha$-SMA). ${ }^{182}$ Larger stress fibers are indicative, all things being equal, of larger forces. ${ }^{30}$ Anchored gel assays have been used to probe the differentiation of fibroblasts into myofibroblasts-a contractile cell type important for mid-term wound healing responses and responsible for tissue fibrogenesis (reviewed in Tomasek et al.). ${ }^{194}$

\section{Traction: Stress Fiber-Independent Force Generation}

Cells in floating or unanchored gels exert forces on the ECM via a stress fiber-independent mechanism. In vivo in dermal tissue, fibroblasts behave similarly to those in relaxed in vitro gels in that they do not exhibit stress fibers. ${ }^{96} \mathrm{It}$ was suggested over 20 years ago that stress fibers required tension for their formation, ${ }^{30}$ and numerous experiments have sustained that view by finding that gel compaction in relaxed collagen gels does not involve stress fibers. ${ }^{55,80,114}$ Recent work is continuing to focus on elucidating the mechanisms by which cells generate forces without stress fibers.

Cells in relaxed 3D collagen gels exert forces to contract that matrix without the presence of stress fibers, and do not require fibronectin to interact with their 3D matrix. Vanni and colleagues showed that cells within 3D collagen gels can contract those gels without visible stress fibers and, using GFP- $\alpha$-actinin and YFP- $\beta$-actin to visualize actin fibers near the cell membrane, showed that forces were instead generated by the cortical CSK. ${ }^{202}$ They estimated this force at $60 \mathrm{nN}$ for a single pseudopod cell process which is relatively small compared to forces generated by stress fibers, but significant as it can clearly reorganize the local collagen matrix. A contracting gel assay was used by another group to postulate a per-cell traction force parameter of $2.73 \times 10^{-4} \mathrm{dyn} / \mathrm{cm}^{2},^{13}$ and to develop the anisotropic biphasic theory for modeling cell and gel mechanics. ${ }^{14}$

Fibroblasts also appear to be able to switch between contractile (stress fiber-positive) and migratory (stress fibernegative) phenotypes based on their mechanical environment. Using a contracting rod assay that compacts in the radial dimension but not axially, Shreiber, Barocas, and Tranquillo showed that once fibroblasts had compacted the matrix, they reverted to a migratory phenotype. ${ }^{179}$ This suggests that reversion and cell migration out of a wound might be the reason for the absence of myofibroblasts in a wound after it is closed. ${ }^{194}$ The appearance of this wound-healinglike behavior in a system without inflammatory factors or immune cells demonstrated the importance of mechanical cues in this critical cellular function.

\section{Compaction: Stress Fiber-Dependent Force Generation}

Although cells can contract collagen gels without stress fibers, the cell must express the contractile machinery of stress fibers to exert large forces on its substrate, through focal adhesions or 3D-matrix adhesions. While $\alpha$-SMA is not strictly necessary for stress fiber formation, the appearance of $\alpha$-SMA in stress fibers is used as a marker for the emergence of the myofibroblast cell phenotype and is associated with highly contractile cells. ${ }^{96}$ When incubated in media with exogenous TGF- $\beta_{1}$ (which promotes $\alpha$-SMA expression), fibroblasts contract their collagen matrix more strongly in both floating and anchored matrices, enhanced stress fiber formation in anchored matrices, ${ }^{6}$ and separately fibroblasts transfected with $\alpha$-SMA have been shown to contract their matrices to a greater extent than those transfected with $\alpha$-cardiac- or $\beta$ - or $\gamma$-cytoplasmic actin. ${ }^{95}$ These increases in stress fibers were not due to an increase in total actin, but specifically an increase in $\alpha$-SMA as measured by Western blots. Blocking the adhesion of the cells to the substrate by using an anti- $\beta_{1}$ integrin antibody blocked the upregulation of $\alpha$-SMA, even in the presence of TGF- $\beta_{1}$. All these results indicate that TGF- $\beta_{1}$ is a potent regulator of $\alpha$-SMA expression and cell contractility, but that this regulation is dependent on the fibroblast being anchored to a matrix that is under tension.

The differentiation of fibroblasts to myofibroblasts is now understood to be dependent on adhesion to the matrix, presence of TGF- $\beta$ (whether exogenous or endogenously upregulated by mechanical stress), presence of cellular fibronectin, ${ }^{177}$ and tension in the extracellular matrix (reviewed in Hinz and Gabbiani). ${ }^{96}$ Ehrlich and Rajaratnam showed that from an initial population of fibroblasts, the cells differentiate into myofibroblasts in areas of a collagen gel under stress while those in stress-free regions do not 
differentiate (i.e., they do not form stress fibers). ${ }^{55}$ Although the mechanisms by which the fibroblasts sense the tension in the matrix and the exact biochemical mechanisms by which all the steps of differentiation and contraction are carried out remain unknown, it seems clear that stress fibermediated matrix contraction is a result of myofibroblast differentiation, and that cells can also contract a relaxed matrix in the absence of stress fibers via a non stress fiberregulated mechanism.

\section{Cell Response to Substrate Compliance or Stored Stresses}

It is now clear that cell behavior is extremely sensitive to the compliance or stiffness of their matrix. A recent study by Yeung et al. on fibroblasts and endothelial cells on collagenor fibronectin-coated polyacrylamide gels showed a sharp transition between the absence of actin stress fibers for cells on soft gels to expression of actin stress fibers when the $2 \mathrm{D}$ substrate stiffness was increased above $3 \mathrm{kPa} .{ }^{223}$ The differences between the morphology and stress fiber expression vanish if the cells are allowed to make cellcell contact; under these conditions all cells express stress fibers. Both fibroblasts and endothelial cells spread more fully and quickly on stiffer matrices, but neutrophils proved insensitive to substrate stiffness, spreading with equal efficacy on surfaces spanning the range of stiffnesses studied. Another study on the spreading of smooth muscle cells on collagen-coated polyacrylamide showed similar trends, but also demonstrated that the slight over-expression of actin via the expression of a GFP-fusion actin can push a cell into a stress fiber regime even on moderately soft gels (about $1 \mathrm{kPa}){ }^{58}$ Taken together, these findings demonstrate that cells with mechanical functions are sensitive to mechanical cues that other cells (such as neutrophils) completely ignore.

Although little is known about the effects of 3D matrix stiffness on embedded cells, there is evidence to suggest that cells will respond in $3 \mathrm{D}$ in a similar fashion to that in the 2D surface studies described earlier. Fibroblasts cultured in anchored 3D collagen matrices develop a stellate morphology in contrast to the dendritic morphology seen in cells in relaxed 3D collagen matrices ${ }^{81}$ and they use different signaling pathways to regulate gel contraction after the release of the gel from its anchoring points. ${ }^{82}$ It seems likely that the local fiber compliance determines whether or not cells can express stress fibers and focal adhesions, and therefore determines the cells' ability to remodel the collagen mesh via contraction. ${ }^{190}$

Fibroblasts can also respond to substrate compliance by altering the mechanical environment via the generation of new matrix components, proteolysis of existing matrix, and communication with neighboring cells. Lack of matrix stiffness, for example, leads fibroblasts to downregulate collagen XII mRNA and protein expression. ${ }^{196}$ In 3D vs. 2D cultures, fibroblasts increase the ratio of colla- gen degradation to production, ${ }^{146}$ increase production of decorin and dermatan sulfate glycosaminoglycan, ${ }^{121}$ and express increased levels of VEGF and HGF in 3D vs. 2D culture, ${ }^{154}$ although whether these responses are due to the dimensionality of the environment or the substrate stiffness remains undetermined.

Although fibroblasts and smooth muscle cells are investigated more frequently in mechanobiology assays due to their known sensitivity to mechanical stimuli, other cells have been shown to respond morphologically to differences in the mechanical stiffness of their environment. In a recent investigation, Flanagan et al. showed that neurons branch more frequently on soft matrigel-coated polyacrylamide gels than stiff ones. ${ }^{66}$ As noted earlier, the soft gel might more closely mimic the $3 \mathrm{D}$ environment than a stiffer gel if that low stiffness is due to entropy in the matrix architecture.

\section{CELL RESPONSE TO 3D MECHANICAL ENVIRONMENTS}

\section{Fibroblast Response to Tension and Compression}

As observed by many investigators, stress fibers are rarely seen in fibroblasts in vivo except in tissues which undergo significant and consistent mechanical loading, such as tendon. ${ }^{157}$ Fibroblasts can also express stress fibers when wound healing or fibrotic pathways are activated which causes them to differentiate into myofibroblasts. ${ }^{81,194}$ In short-term cultures in relaxed 3D collagen gels, this differentiation pathway can be induced by exogenous TGF- $\beta,{ }^{86,190}$ but stress fibers can also appear after fibroblasts are allowed to contract the gel for several days ${ }^{95}$ which decreases organizational entropy and thus allows matrix tension to be sustained. ${ }^{160}$

The alignment of cells in a gel with imposed stress has been repeatedly investigated, but it remains unclear how much of the cell alignment is a passive process and how much is an active cellular response to the force. Girton, Barocas, and Tranquillo recently showed that both collagen fibers and cells in a 3D collagen gel aligned perpendicular to the applied compression. ${ }^{78}$ In contrast, cells and fibers under tension align parallel to the direction of stress. ${ }^{54}$ It is possible that the fibers were aligning passively under the load, as seen in acellular collagen samples, ${ }^{160}$ and that the cells were merely reporting fiber alignment, but the low levels of maximum strain reported during this experiment $(0.2 \%)$ make that seem unlikely. ${ }^{54}$ In this case, it seems more likely that the cells are aligning in order to deposit more collagen along this direction, ${ }^{18}$ and thus shield themselves from strain. ${ }^{54}$ Indeed, when cells are exposed to external stress, they can reinforce their local environment by producing more ECM. This has been seen in $2 \mathrm{D}$, where cyclic strain induced smooth muscle cells to synthesize collagen, hyaluronate, and chondroitin sulfate, ${ }^{122}$ as well as in 3D, where stretch increased collagen XII mRNA and 
protein expression in fibroblasts. ${ }^{196}$ The evidence for both cellular alignment and increased matrix synthesis in fibroblasts subjected to imposed 3D matrix stress suggests that the cells are reinforcing their environment in the most efficient way possible: by concentrating reinforcement in the principle direction of strain. ${ }^{54,96}$

Externally applied stretch can also be shown to have a direct and immediate effect on cytoskeletal networks. Sawada and Sheetz prepared cell-free cytoskeletal networks by plating mouse fibroblasts onto collagen-coated silicone and then destroying the cell membrane with a detergent wash. These networks bound exogenously supplied paxillin at the focal adhesions when the networks were stretched, ${ }^{170}$ and binding of paxillin was inhibited by phenylarsine oxide just as in vivo. When Costa and colleagues grew aortic endothelial cells on pre-stretched fibronectin-coated silicone substrates and then allowed those substrates to suddenly contract, they found that the response of the cytoskeleton varied considerably depending on the rate of shortening. ${ }^{41}$ If shortening occurred very quickly $\left(5 \% \mathrm{~s}^{-1}\right.$ or greater), the actin cytoskeleton buckled with a very short periodicity (well below its persistence length) and then completely disassembled within $5 \mathrm{~s}$, only to re-form $60 \mathrm{~s}$ later. Shortening the cells on a slower time scale yielded no such dramatic effects; in fact, no effect could be seen at all if the shortening strain rate was $0.5 \% \mathrm{~s}^{-1}$ or less. Taken together, these findings indicate that the cytoskeleton is a very early link in the mechanotransduction chain that leads to the changes in gene expression, cell differentiation, migration and alignment discussed earlier. However, it is clear that in non-affine 3D networks, the cytoskeleton may be buffered from such direct and powerful mechanical input.

Finally, compressive stresses in 3D culture systems have been recently explored in a 3D tissue engineered airway wall model, which mimics the airway mucosa with lung fibroblasts and epithelial cells. ${ }^{37}$ In this model, both static and dynamic compressive stresses upregulated matrix remodeling proteins and induced myofibroblast differentiation, among other effects.

\section{Cell Response to Interstitial Flow}

Interstitial fluid flow, which refers to fluid flow through the 3D matrix (as opposed to flow across the surface of cells, as in endothelial cell response to fluid shear stress), exists between the blood and lymphatic capillaries as lymph forms ${ }^{185}$ as well as in dynamically compressed tissues like bone and cartilage. ${ }^{83,116}$ Furthermore, because inflammation and angiogenesis both involve factors that increase vessel permeability (i.e., vascular endothelial growth factor or VEGF), interstitial flow is locally increased during wound healing and inflammation, and may be enhanced from angiogenic tumors into the peripheral stroma. Cellular response to interstitial flow is an emerging area of 3D mechanobiology research, due to its potential importance in cartilage remodeling ${ }^{83}$ and bone development, ${ }^{116} \mathrm{mi}-$ crovascular development and remodeling, ${ }^{92,143}$ tumor drug delivery, ${ }^{104}$ lymphangiogenesis, ${ }^{21}$ and in vasoconstriction responses. ${ }^{212}$ Interstitial flow (through the medial layer of the blood vessel wall) has also been implicated in the vascular remodeling that leads to intimal hyperplasia. ${ }^{188,192}$

It was recently shown that fibroblasts subjected to interstitial flow while embedded in a 3D matrix aligned perpendicularly to the direction of flow ${ }^{145}$ and differentiated into myofibroblasts as indicated by the upregulation of $\alpha$-smooth muscle actin via autocrine upregulation of TGF- $\beta_{1} \cdot{ }^{144}$ Another recent study showed that blood and lymphatic endothelial cells subjected to interstitial flow responded very differently under 3D vs. 2D fluid shear stress in distinct cell-type-dependent fashions. ${ }^{143}$ Lymphatic endothelial cells formed large vacuoles and long extensions when subjected to interstitial flow for 6 days, while blood endothelial cells formed extensive multi-cellular structures, many of which contained lumen. Blood endothelial cells also tended to aggregate in static control cultures whereas lymphatic endothelial cells remained viable as isolated single cells spread through the 3D collagen gel. These differences in behavior, both between cell types and between static $v s$. flow conditions, may be due to their differing environments and functions in vivo. ${ }^{143}$

Tada and Tarbell have shown in a theoretical model that even smooth muscle cells (SMCs) normally considered shielded from blood flow may hypothetically be affected by transmural flow to a surprising degree: the fenestral pore system may focus the small amount of transmural flow onto SMCs in the vessel wall and subject them to appreciable shear stress. ${ }^{187}$ Indeed, recent in vivo work by the same group demonstrates a correlation between the myogenic response of SMCs and transmural fluid filtration through the arteriolar wall. ${ }^{111}$ Cell culture experiments comparing the effects of shear stress on SMCs in $3 \mathrm{D}$ collagen gels $v s$. plated on 2D collagen-coated surfaces showed the SMCs to be much less responsive to flow in $3 \mathrm{D}$ than in $2 \mathrm{D}$, but both still significantly increased production of prostaglandins compared to those under static conditions. $^{212}$ This experiment provides evidence that the 3D environment may either buffer fluid shear stress on cells or increase their tolerance to shear; however, more work is needed to elucidate the mechanisms underlying these differences.

Interstitial flow differs from 2D flow in many ways. First and most obviously, the 2D case involves shear stress on the luminal side with matrix adhesion on the abluminal side; this means that the stress is not necessarily transmitted to the cell through the ECM, e.g. via integrin receptors. However, recent work is revealing the importance of the glycocalyx, a layer of membrane-bound macromolecules on the apical cell surface, in how the cell senses shear stress. It was recently suggested that the glycocalyx projects into the fluid 
space, and converts the hydrodynamic load of fluid shear stress into torque acting on the cortical actin network just below the apical membrane surface. ${ }^{215}$ Recent experiments have shown that the remodeling of the dense actin bands and relocation of vinculin visible under flow with the glycocalyx intact were inhibited or significantly decreased in the absence of glycocalyx layers, whether due to a lack of serum proteins or the presence of heparinase. ${ }^{193}$ This suggests that a 3D-like environment is indeed necessary for sensing even "2D shear stress," and likewise, it is possible that cells in 3D sense interstitial flow through similar transduction pathways.

Last but not least, it is important to consider that the 3D environment provides a buffering system for the transport and storage of most cell-cell signaling molecules and morphogens, and that this is likely to be an important influence on how cells respond to dynamic stresses in 3D. For example, VEGF, TGF- $\beta$, bFGF, and other morphogens exist in vivo bound to the ECM via heparan sulfate. ${ }^{62,63,128,173} \mathrm{In}$ terstitial flow, no matter how small, would alter the extracellular distribution of any secreted molecule, and would also alter the way that matrix-bound morphogens are released, since proteolysis by the cell would also be influenced by interstitial flow. ${ }^{186}$ In fact, interstitial fluid flow may actually facilitate the creation of increasing autocrine gradients of morphogen relative to a cell, if those morphogens were liberated from the matrix by soluble proteases secreted by the cell, as a recent study demonstrated. ${ }^{92}$ Matrix proteolysis and deposition can also be affected by interstitial flow, as shown in articular cartilage under dynamic compression. ${ }^{75,156}$ Thus, interstitial flow may strongly influence remodeling and morphogenesis in ways that do not require mechanosensing by the cell, although this area is nascent within the field of mechanobiology and needs more study.

\section{IMAGING OF CELL-MATRIX INTERACTIONS IN 3D USING CONFOCAL MICROSCOPY}

Cells embedded in 3D gels are protected on all sides from direct physical manipulation by their substrate; thus, optical methods are the best way to obtain information about these cells during an experiment. Because of heterogeneity in the way a matrix transmits stress to a cell, as discussed in Section 2, methods that extract proteins or RNA from the cells in a gel for later analysis must take into consideration the heterogeneity of mechanical inputs. Fortunately, existing light-based technologies such as GFP transfection ${ }^{33}$ and confocal microscopy make 3D cell mechanobiology experiments feasible.

Cells embedded in a translucent hydrogel such as collagen or fibrin are easily observed under wide-field, laser scanning confocal (LSCM), two-photon, and spinning disk confocal microscopy. Staining protocols must often be modified to stain cells embedded in 3D gels to accom- modate the longer time required for antibodies to diffuse, but generally, immunostaining can be done in 3D gels and cells can be transfected with GFP fusion proteins for live cell imaging.

Briefly, confocal microscopy makes use of the physical principles of the pinhole camera ${ }^{134}$ to gather light from an extremely narrow plane of focus. Laser light is fired through an emission pinhole and sent through the lens into the sample. Return light, either reflected or emitted from the fluorophores in the sample, returns through the lens and encounters another pinhole aperture just in front of the light detector. This second pinhole aperture rejects any light not originating from a specific plane inside the sample. In LSCM, the laser scans through the sample in $x$ and $y$, illuminating one pixel at a time and collecting sample light from one pixel at a time, while a motorized turret or a piezoelectric galvometer steps the focal plane in $z$ after each slice of data is collected, which provides for 3D optical data acquisition. This one-pixel-at-a-time mode of operation is slow but delivers good spatial resolution.

Using LSCM, an investigator can use confocal reflectance microscopy to determine the location of matrix fibers without fixing and staining a sample. The confocal reflectance technique is limited to matrices with fibers above a diameter of approximately $200 \mathrm{~nm}$, and cannot be readily used in depths in excess of $150 \mu \mathrm{m}$ in the gel, but it allows information to be gathered about the local fiber configuration around a cell (Fig. 3). Examples of this technique include monitoring fiber alignment in a collagen matrix under tension ${ }^{206}$ and observing cell-matrix interactions during cell migration through a collagen matrix. ${ }^{71}$

While 3D imaging has several unique technical challenges (spherical aberration, high magnification lens working distance, etc.) ${ }^{102,159,204}$ perhaps the most obvious and intractable is that of increased image acquisition time. In LSCM, the image acquisition time depends both on the number of focal planes (or $z$ slices) and the resolution of each plane. Cells on 2D surfaces typically only rise 10-12 $\mu \mathrm{m}$ above the surface, but cells in 3D gels may occupy $100 \mu \mathrm{m}$ or more in the $z$ direction. If the cells are fixed and stained, the longer time needed to collect data in 3D vs. 2D (up to 10 times as long) may not be a concern. However, these long times can be phototoxic to live cells, particularly for repeated imaging as in a dynamic study. Acquisition speed can be traded for resolution (in each $x y$ plane and in $z$ ) to some extent.

A spinning disk confocal microscope makes use of the confocal principle via a pair of rotating disks with multiple apertures or lenses to provide confocal illumination and filtering. Typically, spinning disk confocal systems use CCD cameras to capture light one plane at a time in contrast to the slower laser scanning method. The amount of time for 3D information to be acquired depends primarily on the speed of the motor stepping the focal plane through the sample, as well as the time required to switch illumination 
wavelengths when two or more wavelengths are used. Spinning disk confocal microscopes and wide-field microscopes are better suited to high-speed 3D imaging, but are more difficult to use for confocal reflection microscopy.

LSCM systems can be used in conjunction with GFP technologies to perform photobleaching experiments on live cells to track movement of intracellular proteins. Fluorescence recovery after photobleaching (FRAP) and fluorescence loss in photobleaching (FLIP) both exploit photobleaching a fluorescent tracer to measure the mobility of a protein in its intracellular space. The scanning laser can also be used to photo-activate the fluorescence of a chimera protein in a small area in the cell. Fluorescence resonance energy transfer (FRET) is a technique that uses the excited coupling of one fluorophore with another spectrally overlapping dye to reveal when two proteins are in close contact. FRET only works at extremely close range due to the method of energy transfer, but it can be used with any kind of fluorescence microscope system.

Examples of recent mechanobiology experiments using high resolution live imaging of cells on 2D surfaces include cytoskeletal strain of endothelial cells under shear ${ }^{93}$ and fibroblasts under stretch, ${ }^{135}$ cytoskeletal and substrate deflection during fibroblast migration on poly(dimethylsiloxane) (PDMS) posts, ${ }^{191}$ focal adhesion dynamics during cell migration, ${ }^{209}$ and actin dynamics during cell migration ${ }^{127}$ and cell spreading. ${ }^{11,207,224}$ Very few published examples exist of live confocal imaging of cells in 3D; these include observations of a cell undergoing tensile strain by Voytik-Harbin's group ${ }^{206}$ and the studies of cell migration by Friedl's group ${ }^{218}$ discussed in Section 4. Imaging live cells undergoing mechanical strain in 3D environments remains very difficult and poses one of the major challenges in broadening our understanding of mechanobiology in 3D.

\section{CHALLENGES FOR THE FUTURE}

The way cells sense and respond to their mechanical environment in three dimensions is complex and dynamic, and results from an integrated effect of the mechanical behavior of the ECM and cytoskeleton, the biology of the ECM and mechanotransduction, and the transport of secreted molecules whose local gradients affect cell response. While 2D experiments continue to provide valuable insights into cytoskeletal mechanics and mechanisms cells use to interact with their physical surroundings, more work in 3D environments is needed to put those results in the context of 3D mechanobiology. This review has demonstrated some of the differences between cell behavior in 2D vs. 3D environments and discussed some of the physical characteristics of 3D fibrous hydrogels that may be important in governing cell mechanobiology in such environments.

We can interpret the role of energy dissipation, and the subsequent non-affine deformation of fibrous matrices, as a sort of mechanical buffering system that could shield cells embedded in the ECM from external forces. When a tissue has a stress imposed on it, some of the mechanical energy will be absorbed in reducing the structural disorder of the matrix, some will be dissipated by fiber bending and slipping, and some will be stored in the fibers. The amount of disorder in the matrix serves as an indication of the importance of this effect in a given tissue. Cells in tissues with high degrees of structural order such as bone need a certain level of sensitivity to their mechanical environment so that they can fine-tune that environment to ensure proper function; a highly ordered matrix does not dampen mechanical signals like the more disorderly one. ${ }^{157}$

As we have suggested, new methodologies for observing and manipulating cells in 3D environments will be required to investigate the ways that cells interact with these types of surroundings. Optical methods are likely candidates due to the minimal interaction that light has with most cells and substrates, and we have briefly covered some of the aspects of optical technologies currently in use in cell biology experiments. The challenge for the future of $3 \mathrm{D}$ mechanobiology is to design experiments that can capture detailed information about cellular interactions with 3D environments, while integrating information gleaned about protein interactions and cytoskeletal mechanisms from existing and future $2 \mathrm{D}$ experiments.

\section{ACKNOWLEDGMENTS}

The authors are grateful to the Whitaker Foundation (graduate fellowship to J. A. P.), the National Science Foundation (BES-0134551 to M.A.S.) and the NIH (R01 HL 075217 to M. A. S.) for funding.

\section{REFERENCES}

${ }^{1}$ Agoram, B., and V. H. Barocas. Coupled macroscopic and microscopic scale modeling of fibrillar tissues and tissue equivalents. J. Biomech. Eng. 123:362-369, 2001.

${ }^{2}$ Allen, T. D., S. L. Schor, and A. M. Schor. An ultrastructural review of collagen gels, a model system for cell matrix, cellbasement membrane and cell-cell interactions. Scan. Electron Microsc. 1984(I):375-390, 1984.

${ }^{3}$ Altman, G. H., R. L. Horan, I. Martin, J. Farhadi, P. R. H. Stark, J. C. R. Volloch, G. Vunjak-Novakovic, and D. L. Kaplan. Cell differentiation by mechanical stress. FASEB J. Online December 28, 2001, doi: 10.1096/fj.01-0656fje, 2001.

${ }^{4}$ Anand, S., J.-H. Wu, and S. L. Diamond. Enzyme-mediated proteolysis of fibrous biopolymers: Dissolution front movement in fibrin or collagen under conditions of diffusive or convective transport. Biotechnol. Bioeng. 48:89-107, 1995.

${ }^{5}$ Arnaout, M. A., S. L. Goodman, and J.-P. Xiong. Coming to grips with integrin binding to ligands. Curr. Opin. Cell Biol. 14:641-651, 2002.

${ }^{6}$ Arora, P. D., N. Narani, and C. A. G. McCulloch. The compliance of collagen gels regulates transforming growth factor- $\beta$ induction of $\alpha$-smooth muscle actin in fibroblasts. Am.J. Pathol. 154:871-882, 1999.

${ }^{7}$ Avila, J., and J. D. Nido. Control of microtubule polymerization and stability. In: The Cytoskeleton: Structure and Assembly, 
edited by J. E. Hekseth and I. F. Pryme, Vol. 1. Greenwich: JAI Press, 1995, pp. 47-85.

${ }^{8}$ Bailey, M., H. Xiao, M. Ogle, and N. Vyavahare. Aluminum chloride pretreatment of elastin inhibits elastolysis by matrix metalloproteinases and leads to inhibition of elastin-oriented calcification. Am. J. Pathol. 159:1981-1986, 2001.

${ }^{9}$ Balaban, N. Q., U. S. Schwarz, D. Riveline, P. Goichberg, G. Tzur, I. Sabanay, D. Mahalu, S. Safran, A. Bershadsky, L. Addadi, and B. Geiger. Force and focal adhesion assembly: A close relationship studied using elastic micropatterned substrates. Nature Cell Biol. 3:466-472, 2001.

${ }^{10}$ Bale, M. D., M. F. Müller, and J. D. Ferry. Rheological studies of creep and creep recovery of unligated fibrin clots: Comparison of clots prepared with thrombin and ancrod. Biopolymers 24:461-482, 1985.

${ }^{11}$ Ballestrem, C., B. Wehrle-Haller, and B. A. Imhof. Actin dynamics in living mammalian cells. J. Cell Sci. 111:1649-1658, 1998.

${ }^{12}$ Barbee, K. A., P. F. Davies, and R. Lal. Shear stress-induced reorganization of the surface topography of living endothelial cells imaged by atomic force microscopy. Circ. Res. 74:163171, 1994.

${ }^{13}$ Barocas, V. H., A. G. Moon, and R. T. Tranquillo. The fibroblast-populated collagen microsphere assay of cell traction force: Part 2. Measurement of the cell traction parameter. J. Biomech. Eng. 117:161-170, 1995.

${ }^{14}$ Barocas, V. H., and R. T. Tranquillo. An anisotropic biphasic theory of tissue-equivalent mechanics: The interplay among cell traction, fibrillar network deformation, fibril alignment, and cell contact guidance. J. Biomech. Eng. 119:137-145, 1997.

${ }^{15}$ Barry, S. T., and D. R. Critchley. The RhoA-dependent assembly of focal adhesions in Swiss 3 T3 cells is associated with increased tyrosine phosphorylation and the recruitment of both pp125FAK and protein kinase C- $\delta$ to focal adhesions. J. Cell Sci. 107:2033-2045, 1994.

${ }^{16}$ Bell, E., B. Ivarsson, and C. Merrill. Production of a tissue-like structure by contraction of collagen lattices by human fibroblasts of different proliferative potential in vitro. Proc. Natl. Acad. Sci. U.S.A. 76:1274-1278, 1979.

${ }^{17}$ Bellows, C. G., A. H. Melcher, and J. E. Aubin. Association between tension and orientation of periodontal ligament fibroblasts and exogenous collagen fibres in vitro. J. Cell Sci. 58:125138, 1982.

${ }^{18}$ Birk, D. E., and R. L. Trelstad. Extracellular compartments in matrix morphogenesis-Collagen fibril, bundle, and lamellar formation by corneal fibroblasts. J. Cell Biol. 99:2024-2033, 1984.

${ }^{19}$ Bissell, M. J., D. C. Radisky, A. Rizki, V. M. Weaver, and O. W. Petersen. The organizing principle: Microenvironmental influences in the normal and malignant breast. Differentiation 70:537-546, 2002.

${ }^{20}$ Blombäck, B., K. Carlsson, B. Hessel, A. Liljeborg, R. Procyk, and N. Åslund. Native fibrin gel networks observed by 3D microscopy, permeation and turbidity. Biochim. Biophys. Acta 997:96-110, 1989.

${ }^{21}$ Boardman, K. C., and M. A. Swartz. Interstitial flow as a guide for lymphangiogenesis. Circ. Res. 92:801-808, 2003.

${ }^{22}$ Bollard, T. D., L. Blanchoin, and R. D. Mullins. Molecular mechanism controlling actin filament dynamics in nonmuscle cells. Annu. Rev. Biophys. Biomol. Struct. 29:545576, 2000.

${ }^{23}$ Bornstein, P., and E. H. Sage. Matricellular proteins: Extracellular modulators of cell function. Curr. Opin. Cell Biol. 14:608616, 2002.
${ }^{24}$ Brightman, A. O., B. P. Rajwa, J. E. Sturgis, M. E. McCallister, J. P. Robinson, and S. L. Voytik-Harbin. Time-lapse confocal reflection microscopy of collagen fibrillogenesis and extracellular matrix assembly in vitro. Biopolymers 54:222234, 2000.

${ }^{25}$ Brock, A., E. Chang, C.-C. Ho, et al. Geometric determinants of directional cell motility revealed using microcontact printing. Langmuir 19:1611-1617, 2003.

${ }^{26}$ Bromberek, B. A., P. A. J. Enever, D. I. Shreiber, M. D. Caldwell, and R. T. Tranquillo. Macrophages influence a competition of contact guidance and chemotaxis for fibroblast alignment in a fibrin gel coculture assay. Exp. Cell Res. 275:230-242, 2002.

${ }^{27}$ Brown, A. F. Neutrophil granulocytes: Adhesion and locomotion on collagen substrata and in collagen matrices. J. Cell Sci. 58:455-467, 1982.

${ }^{28}$ Brown, R. A., R. Prajapati, D. A. McGrouther, I. V. Yannas, and M. Eastwood. Tensional homeostasis in dermal fibroblasts: Mechanical responses to mechanical loading in threedimensional substrates. J. Cell. Physiol. 175:323-332, 1998.

${ }^{29}$ Burghardt, W. R., T. K. Goldstick, J. Leneschmidt, and K. Kempka. Nonlinear viscoelasticity and the thrombelastograph: 1. Studies on bovine plasma clots. Biorheol. 32:621-630, 1995.

${ }^{30}$ Burridge, K. Are stress fibres contractile? Nature 294:691-692, 1981.

${ }^{31}$ Butler, P. J., G. Norwich, S. Weinbaum, and S. Chien. Shear stress induces a time- and position dependent increase in endothelial cell membrane fluidity. Am. J. Physiol. Cell Physiol. 280:C962-C969, 2001.

${ }^{32}$ Butler, J. P., I. M. Tolic-Nørrelykke, B. Fabry, and J. J. Fredberg. Traction fields, moments, and strain energy that cells exert on their surroundings. Am. J. Physiol. Cell Physiol. 282:C595C605, 2002.

${ }^{33}$ Chalfie, M., Y. Tu, G. Euskirchen, W. W. Ward, and D. C. Prasher. Green fluorescent protein as a marker for gene expression. Science 263:802-805, 1994.

${ }^{34}$ Chandran, P. L., and V. H. Barocas. Microstructural mechanics of collagen gels in confined compression: Poroelasticitsy, viscoelasticity, and collapse. J. Biomech. Eng. 126:152-166, 2004.

${ }^{35}$ Chandran, P. L. and V. H. Barocas. Affine vs. non-affine fibril kinematics in collagen networks: Theoretical studies of network behavior. J. Biomech. Eng. 2005, in press.

${ }^{36}$ Chen, C. S., M. Mrksich, S. Huang, G. M. Whitesides, and D. E. Ingber. Geometric control of cell life and death. Science 276:1425-1428, 1997.

${ }^{37}$ Choe, M. M.-H, P. H. S. Sporn, and M. A. Swartz. An in vitro airway wall model of remodeling. Am. J. Physiol. Lung Cell. Mol. Physiol. 285:L427-L433, 2003.

${ }^{38}$ Choquet, D., D. P. Felsenfeld, and M. P. Sheetz. Extracellular matrix rigidity causes strengthening of integrin-cytoskeleton linkages. Cell 88:39-48, 1997.

${ }^{39}$ Christensen, R. M., and F. M. Waals. Effective stiffness of randomly oriented fibre composites. J. Composite Mater. 6:518532, 1972.

${ }^{40}$ Ciano, P. S., R. B. Colvin, A. M. Dvorak, J. McDonagh, and H. F. Dvorak. Macrophage migration in fibrin gel matrices. Lab. Invest. 54:62-70, 1986.

${ }^{41}$ Costa, K. D., W. J. Hucker, and F. C.-P. Yin. Buckling of actin stress fibers: A new wrinkle in the cytoskeletal tapestry. Cell Motil. Cytoskeleton 52:266-274, 2002.

${ }^{42}$ Couchman, J. R., and D. A. Rees. The behaviour of fibroblasts migrating from chick heart explants: Changes in adhesion, locomotion and growth, and in the distribution of actomyosin and fibronectin. J. Cell Sci. 39:149-165, 1979. 
${ }^{43}$ Cowin, S. C. The mechanical and stress adaptive properties of bone. Ann. Biomed. Eng. 11:263-295, 1983.

${ }^{44} \mathrm{Cox}, \mathrm{H}$. L. The elasticity and strength of paper and other fibrous materials. Br. J. Appl. Phys. 3:72-79, 1952.

${ }^{45}$ Crevensten, G., A. J. L. Walsh, D. Ananthakrishnan, et al. Intervertebral disc cell therapy for regeneration: Mesenchymal stem cell implantation in rat intervertebral discs. Ann. Biomed. Eng. 32:430-434, 2004.

${ }^{46}$ Cukierman, E., R. Pankov, and K. M. Yamada. Cell interactions with three-dimensional matrices. Curr. Opin. Cell Biol. 14:633639, 2002.

${ }^{47}$ Cukierman, E., R. Pankov, D. R. Stevens, and K. M. Yamada. Taking cell-matrix adhesions to the third dimension. Science 294:1708-1712, 2001.

${ }^{48}$ Dalby, M. J., M. O. Riehle, S. J. Yarwood, C. D. W. Wilkinson, and A. S. G. Curtisa. Nucleus alignment and cell signaling in fibroblasts: Response to a micro-grooved topography. Exp. Cell Res. 284:274-282, 2003.

${ }^{49}$ Davies, P. F., J. Zilberberg, and B. P. Helmke. Spatial microstimuli in endothelial mechanosignaling. Circ. Res. 92:359-370, 2003.

${ }^{50}$ Delacourt, C., P.-H. Jarraeu, and J. Bourbon. Développement alvéolaire normal et pathologique [French]. Rev. Mal. Respir. 20:373-383, 2003.

${ }^{51}$ Dubey, N., P. C. Letourneau, and R. T. Tranquillo. Guided neurite elongation and Schwann cell invasion into magnetically aligned collagen in simulated peripheral nerve regeneration. Exp. Neurol. 158:338-350, 1999.

${ }^{52}$ Dvorak, H. F. Tumors: Wounds that do not heal. N. Engl. J. Med. 315:1650-1659, 1986.

${ }^{53}$ Eastwood, M., D. A. McGrouther, and R. A. Brown. A culture force monitor for measurement of contraction forces generated in human dermal fibroblast cultures: Evidence for cell-matrix mechanical signalling. Biochim. Biophys. Acta 1201:186-192, 1994.

${ }^{54}$ Eastwood, M., V. C. Mudera, D. A. McGrouther, and R. A. Brown. Effect of precise mechanical loading on fibroblast populated collagen lattices: Morphological changes. Cell Motil. Cytoskeleton 40:13-21, 1998.

${ }^{55}$ Ehrlich, H. P., and J. B. M. Rajaratnam. Cell locomotion forces versus cell contraction forces for collagen lattice contractionAn in vitro model of wound contraction. Tissue Cell 22:407417, 1990.

${ }^{56}$ Ehrmann, R. L., and G. O. Gey. The growth of cells on a transparent gel of reconstituted rat-tail collagen. J. Natl. Cancer Inst. 16:1375-1403, 1956.

${ }^{57}$ Elsdale, T., and J. Bard. Collagen substrata for studies on cell behavior. J. Cell Biol. 54:626-637, 1972.

${ }^{58}$ Engler, A., L. Bacakova, C. Newman, A. Hategan, M. Griffin, and D. Discher. Substrate compliance versus ligand density in cell on gel responses. Biophys. J. 86:617-628, 2004.

${ }^{59}$ Entschladen, F., B. Niggemann, K. S. Zänker, and P. Friedl. Differential requirement of protein tyrosine kinases and protein kinase $\mathrm{C}$ in the regulation of $\mathrm{T}$ cell locomotion in three-dimensional collagen matrices. J. Immunol. 159:32033210, 1997.

${ }^{60}$ Estes, B. T., J. M. Gimble, and F. Guilak. Mechanical signals as regulators of stem cell fate. Curr. Top. Dev. Biol. 60:91-126, 2004.

${ }^{61}$ Etienne-Manneville, S. Actin and microtubules in cell motility: Which one is in control? Traffic 5:470-477, 2004.

${ }^{62}$ Fairbrother, W. J., M. A. Champe, H. W. Christinger, B. A. Keyt, and M. A. Starovasnik. Solution structure of the heparinbinding domain of vascular endothelial growth factor. Structure 6:637-648, 1998.
${ }^{63}$ Fannon, M., K. E. Forsten, and M. A. Nugent. Potentiation and inhibition of bFGF binding by heparin: A model for regulation of cellular response. Biochemistry 39:1434-1445, 2000.

${ }^{64}$ Fanti, L. A., and E. D. Glandt. Partitioning of spherical particles into fibrous matrices: 1. Density-functional theory. J. Colloid Interface Sci. 135:385-395, 1990.

${ }^{65}$ Farquhar, T., P. R. Dawson, and P. A. Torzilli. A microstructural model for the anisotropic drained stiffness of articular-cartilage. J. Biomech. Eng. 112:414-425, 1990.

${ }^{66}$ Flanagan, L. A., Y.-E. Ju, B. Marg, M. Osterfield, and P. A. Janmey. Neurite branching on deformable substrates. Neuroreport 13:2411-2415, 2002.

${ }^{67}$ Forgacs, G., S. A. Newman, B. Hinner, C. W. Maier, and E. Sackmann. Assembly of collagen matrices as a phase transition revealed by structural and rheological studies. Biophys. $J$. 84:1272-1280, 2003.

${ }^{68}$ Friedl, P., and E.-B. Bröcker. The biology of cell locomotion within three-dimensional extracellular matrix. Cell. Mol. Life Sci. 57:41-64, 2000.

${ }^{69}$ Friedl, P., and E.-B. Bröcker. Biological confocal reflection microscopy: Reconstruction of three-dimensional extracellular matrix, cell migration, and matrix reorganization. In: Image Analysis: Methods and Applications, edited by D.-P. Häder, 2nd ed. Boca Raton, FL: CRC Press, 2001.

${ }^{70}$ Friedl, P., F. Entschladen, C. Conrad, B. Niggemann, and K. S. Zänker. CD4+ T lymphocytes migrating in three-dimensional collagen lattices lack focal adhesions and utilize $\beta 1$ integrinindependent strategies for polarization, interaction with collagen fibers and locomotion. Eur. J. Immunol. 28:2331-2343, 1998.

${ }^{71}$ Friedl, P., K. Maaser, C. E. Klein, B. Niggemann, G. Krohne, and K. S. Zänker. Migration of highly aggressive MV3 melanoma cells in 3-dimensional collagen lattices results in local matrix reorganization and shedding of $\alpha 2$ and $\beta 1$ integrins and CD44. Cancer Res. 57:2061-2070, 1997.

${ }^{72}$ Friedl, P., K. S. Zänker, and E. B. Bröcker. Cell migration strategies in 3D-extracellular matrix: Differencess in morphology, cell matrix interactions and integrin function. Microsc. Res. Tech. 43:369-378, 1998.

${ }^{73}$ Galbraith, C. G., and M. P. Sheetz. A micromachined device provides a new bend on fibroblast traction forces. Proc. Natl. Acad. Sci. U.S.A. 94:9114-9118, 1997.

${ }^{74}$ Galbraith, C. G., and M. P. Sheetz. Keratocytes pull with similar forces on their dorsal and ventral surfaces. J. Cell Biol. 147:1313-1323, 1999.

${ }^{75}$ Garcia, A. M., M. W. Lark, S. B. Trippel, and A. J. Grodzinsky. Transport of tissue inhibitor of metalloproteinases-1 through cartilage: Contributions of fluid flow and electrical migration. J. Orthop. Res. 16:734-742, 1998.

${ }^{76}$ Gardel, M. L., J. H. Shin, F. C. MacKintosh, L. Mahadevan, P. Matsudaira, and D. A. Weitz. Elastic behavior of cross-linked and bundled actin networks. Science 304:1301-1305, 2004.

${ }^{77}$ Gelse, K., E. Pöschl, and T. Aigner. Collagens-Structure, function, and biosynthesis. Adv. Drug Delivery Rev. 55:15311546, 2003.

${ }^{78}$ Girton, T. S., V. H. Barocas, and R. T. Tranquillo. Confined compression of a tissue-equivalent: Collagen fibril and cell alignment in response to anisotropic strain. J. Biomech. Eng. 124:568-575, 2002.

${ }^{79}$ Girton, T. S., T. R. Oegema, and R. T. Tranquillo. Exploiting glycation to stiffen and strengthen tissue equivalents for tissue engineering. J. Biomed. Mater. Res. 46:87-92, 1999.

${ }^{80}$ Grinnell, F. Fibroblasts, myofibroblasts, and wound contraction. J. Cell Biol. 124:401-404, 1994. 
${ }^{81}$ Grinnell, F. Fibroblast biology in three-dimensional collagen matrices. Trends Cell Biol. 13:264-269, 2003.

${ }^{82}$ Grinnell, F., C. H. Ho, Y.-C. Lin, and G. Skuta. Differences in the regulation of fibroblast contraction of floating versus stressed collagen matrices. J. Biol. Chem. 274:918-923, 1999.

${ }^{83}$ Grodzinsky, A. J., M. E. Levenston, M. Jin, and E. H. Frank. Cartilage tissue remodeling in response to mechanical forces. Ann. Rev. Biomed. Eng. 2:691-713, 2000.

${ }^{84}$ Guidry, C., and F. Grinnell. Studies on the mechanism of hydrated collagen gel reorganization by human skin fibroblasts. J. Cell Sci. 79:67-81, 1985.

${ }^{85}$ Gustavson, K. H. The Chemistry and Reactivity of Collagen. New York: Academic Press, 1956.

${ }^{86}$ Halliday, N. L., and J. J. Tomasek. Mechanical properties of the extracellular matrix influence fibronectin fibril assembly in vitro. Exp. Cell Res. 217:109-117, 1995.

${ }^{87}$ Harris, A. K., D. Stopak, and P. Wild. Fibroblast traction as a mechanism for collagen morphogenesis. Nature 290:249-251, 1981.

${ }^{88}$ Harris, A. K., P. Wild, and D. Stopak. Silicone rubber substrata: A new wrinkle in the study of cell locomotion. Science 208:177-179, 1980

${ }^{89}$ Head, D. A., A. J. Levine, and F. C. MacKintosh. Deformation of cross-linked semiflexible polymer networks. Phys. Rev. Lett. 91:108102, 2003.

${ }^{90}$ Heidemann, S. R., and D. Wirtz. Towards a regional approach to cell mechanics. Trends Cell Biol. 14:160-166, 2004.

${ }^{91}$ Helfand, B. T., L. Chang, and R. D. Goldman. The dynamic and motile properties of intermediate filaments. Annu. Rev. Cell Dev. Biol. 19:445-467, 2003.

${ }^{92}$ Helm, C. E., M. E. Fleury, A. H. Zisch, K. C. Boardman, F. Boschetti, and M. A. Swartz. 3D fluid flow directs capillary morphogenesis via biased amplification of VEGF gradients. Proc. Natl. Acd. Sci. USA. 2005 (in press).

${ }^{93}$ Helmke, B. P., R. D. Goldman, and P. F. Davies. Rapid displacement of vimentin intermediate filaments in living endothelial cells exposed to flow. Circ. Res. 86:745-752, 2000.

${ }^{94}$ Helmke, B. P., A. B. Rosen, and P. F. Davies. Mapping mechanical strain of an endogenous cytoskeletal network in living endothelial cells. Biophys. J. 84:2691-2699, 2003.

${ }^{95}$ Hinz, B., G. Celetta, J. J. Tomasek, G. Gabbiani, and C. Chaponnier. Alpha-smooth muscle actin expression upregulates fibroblast contractile activity. Mol. Biol. Cell. 12:27302741, 2001.

${ }^{96} \mathrm{Hinz}$, B., and G. Gabbiani. Mechanisms of force generation and transmission by myofibroblasts. Curr. Opin. Biotechnol. 14:538-546, 2003.

${ }^{97}$ Hiraoka, N., E. Allen, I. J. Apel, M. R. Gyetko, and S. J. Weiss. Matrix metalloproteinases regulate neovascularization by acting as pericellular fibrinolysins. Cell 95:365-377, 1998.

${ }^{98}$ Huang, H., R. D. Kamm, and R. T. Lee. Cell mechanics and mechanotransduction: Pathways, probes, and physiology. Am. J. Physiol. Cell Physiol. 287:C1-C11, 2004.

${ }^{99}$ Ingber, D. E. Tensegrity: I. Cell structure and hierarchical systems biology. J. Cell Sci. 116:1157-1173, 2003.

${ }^{100}$ Ingber, D. E. Tensegrity: II. How structural networks influence cellular information processing networks. J. Cell Sci. 116:1397-1408, 2003.

${ }^{101}$ Ingber, D. E. Mechanobiology and diseases of mechanotransduction. Ann. Med. 35:564-577, 2003.

${ }^{102}$ Inoué, S. Foundations of confocal scanned imaging in light microscopy. In: Handbook of Biological Confocal Microscopy, edited by J. B. Pawley, 2nd ed., Vol. 1. New York: Plenum Press, 1995, pp. 1-17.
${ }^{103}$ Jain, R. K. Transport of molecules in the tumor interstitium: A review. Cancer Res. 47:3039-3051, 1987.

${ }^{104}$ Jain, R. K. Transport of molecules, particles, and cells in solid tumors. Ann. Rev. Biomed. Eng. 1:241-263, 1999.

${ }^{105}$ Juvinall, R. C., and K. M. Marshek. Fundamentals of Machine Component Design, 2nd ed. New York: Wiley, 1991.

${ }^{106}$ Kahn, L. P., R. J. Carroll, and L. P. Witnauer. Some effects of electrolytes on collagen in solution. Biochim. Biophys. Acta 63:243-254, 1962.

${ }^{107}$ Kamm, R. D. Airway wall mechanics. Ann. Rev. Biomed. Eng. 1:47-72, 1999.

${ }^{108}$ Katz, B.-Z., E. Zamir, A. Bershadsky, Z. Kam, K. M. Yamada, and B. Geiger. Physical state of the extracellular matrix regulates the structure and molecular composition of cell-matrix adhesions. Mol. Biol. Cell. 11:1047-1060, 2000.

${ }^{109}$ Keller, H. E. Objective lenses for confocal microscopy. In: Handbook of Biological Confocal Microscopy, edited by J. B. Pawley. New York: Plenum Press, 1995, pp. 111-126.

${ }^{110}$ Kerin, A., P. Patwari, K. Kuettner, A. Cole, and A. Grodzinsky. Molecular basis of osteoarthritis: Biomechanical aspects. Cell. Mol. Life Sci. 59:27-35, 2002.

${ }^{111}$ Kim, M., N. R. Harris, D. H. Korzick, and J. M. Tarbell. Control of the arteriolar myogenic response by transvascular fluid filtration. Microvasc. Res. 68:30-37, 2004.

${ }^{112} \mathrm{Kjær}$, M. Role of extracellular matrix in adaptation of tendon and skeletal muscle to mechanical loading. Physiol. Rev. 84:649-698, 2004.

${ }^{113}$ Kleinfeld, D., K. H. Kahler, and P. E. Hockberger. Controlled outgrowth of dissociated neurons on patterned substrates. J. Neurosci. 8:4098-4120, 1988.

${ }^{114}$ Knapp, D. M., V. H. Barocas, A. G. Moon, K. Yoo, L. R. Petzold, and R. T. Tranquillo. Rheology of reconstituted type I collagen gel in confined compression. J. Rheol. 41:971-993, 1997.

${ }^{115}$ Knapp, D. M., T. T. Tower, R. T. Tranquillo, and V. H. Barocas. Estimation of cell traction and migration in an isometric cell traction assay. AIChE J. 45:2628-2640, 1999.

${ }^{116}$ Knothe Tate, M. L. Whither flows the fluid in bone? An osteocyte's perspective. J. Biomech. 36:1409-1424, 2003.

${ }^{117}$ Knox, P., S. Crooks, M. C. Scaife, and S. Patel. Role of plasminogen, plasmin, and plasminogen activators in the migration of fibroblasts into plasma clots. J. Cell. Physiol. 132:501-508, 1987.

${ }^{118}$ Kuntz, R. M., and W. M. Saltzman. Neutrophil motility in extracellular matrix gels: Mesh size and adhesion affect speed of migration. Biophys. J. 72:1472-1480, 1997.

${ }^{119}$ Lazarides, E. Actin, $\alpha$-actinin, and tropomyosin interaction in the structural organization of actin filaments in nonmuscle cells. J. Cell Biol. 68:202-219, 1976.

${ }^{120}$ Lazarides, E., and K. Weber. Actin antibody: The specific visualization of actin filaments in non-muscle cells. Proc. Natl. Acad. Sci. U.S.A. 71:2268-2272, 1974.

${ }^{121}$ Lee, P. H. A., J. M. Trowbridge, K. R. Taylor, V. B. Morhenn, and R. L. Gallo. Dermatan sulfate proteoglycan and glycosaminoglycan synthesis is induced in fibroblasts by transfer to a three-dimensional extracellular environment. J. Biol. Chem. 279:48640-48646, 2004.

${ }^{122}$ Leung, D. Y. M., S. Glagov, and M. B. Mathews. Cyclic stretching stimulates synthesis of matrix components by arterial smooth muscle cells in vitro. Science 191:475-477, 1976.

${ }^{123}$ Levick, J. R. Flow through interstitium and other fibrous matrices. Q. J. Exp. Physiol. 72:409-437, 1987.

${ }^{124} \mathrm{Li}$, S., J.-L. Guan, and S. Chien. Biochemistry and biomechanics of cell motility. Ann. Rev. Biomed. Eng. 7:9.1-9.46, 2005. 
${ }^{125}$ Liu, S., D. A. Calderwood, and M. H. Ginsberg. Integrin cytoplasmic domain-binding proteins. J. Cell Sci. 113:3563-3571, 2000.

${ }^{126}$ Longas, M. O., and R. Fleischmajer. Immunoelectron microscopy of proteodermatan sulfate in human mid-dermis. Connect. Tissue Res. 13:117-125, 1984.

${ }^{127}$ Lorenz, M., V. DesMarais, F. Macaluso, R. H. Singer, and J. Condeelis. Measurement of barbed ends, actin polyerization, and motility in live carcinoma cells after growth factor stimulation. Cell Motil. Cytoskeleton 57:207-217, 2004.

${ }^{128}$ Lyon, M., G. Rushton, and J. T. Gallagher. The interaction of the transforming growth factor- $\beta$ s with heparin/heparin sulfate is isoform-specific. J. Biol. Chem. 272:18000-18006, 1997.

${ }^{129}$ Maaser, K., K. Wolf, C. E. Klein, et al. Functional hierarchy of simultaneously expressed adhesion receptions: Integrn $\alpha 2 \beta 1$ but not CD44 mediates MV3 melanoma cell migration and matrix reorganization within three-dimensional hyaluronancontaining matrices. Mol. Biol. Cell 10:3067-3079, 1999.

${ }^{130}$ Maciver, S. K. Microfilament organization and actin-binding proteins. In: The Cytoskelton: Structure and Assembly, edited by J. E. Hesketh and I. F. Pryme, Vol. 1. Greenwich: JAI Press, 1995, pp. 1-45.

${ }^{131}$ Majno, G., G. Gabbiani, B. J. Hirschel, G. B. Ryan, and P. R. Statkov. Contraction of granulation tissue in vitro: Similarity to smooth muscle. Science 173:548-550, 1971.

${ }^{132}$ Meshel, A. S., Q. Wei, R. S. Adelstein, and M. P. Sheetz. Basic mechanism of three-dimensional collagen fibre transport by fibroblasts. Nat. Cell Biol. 7:157-164, 2005.

${ }^{133}$ Mijailovich, S. M., D. Stamenovic, and J. J. Fredberg. Toward a kinetic theory of connective tissue micromechanics. J. Appl. Physiol. 74:665-681, 1993.

${ }^{134}$ Minsky, M. Memoir on inventing the confocal scanning microscope. Scanning 10:128-138, 1988.

${ }^{135}$ Mizutani, T., H. Haga, and K. Kawabata. Cellular stiffness response to external deformation: Tensional homeostasis in a single fibroblast. Cell Motil. Cytoskeleton 59:242-248, 2004.

${ }^{136}$ Mochitate, K., P. Pawelek, and F. Grinnell. Stress relaxation of contracted collagen gels: Disruption of actin filament bundles, release of cell surface fibronectin, and down-regulation of DNA and protein synthesis. Exp. Cell Res. 193:198-207, 1991.

${ }^{137}$ Montesano, R., and L. Orci. Tumor-promoting phorbol esters induce angiogenesis in vitro. Cell 42:469-477, 1985.

${ }^{138}$ Mosesson, M. W., K. R. Siebenlist, and D. A. Meh. The structure and biological features of fibrinogen and fibrin. Ann. N. Y. Acad. Sci. 936:11-30, 2001.

${ }^{139}$ Mrksich, M., C. S. Chen, Y. Xia, L. E. Dike, D. E. Ingber, and G. M. Whitesides. Controlling cell attachment on contoured surfaces with self-assembled monolates of alkanethiolates on gold. Proc. Natl. Acad. Sci. U.S.A. 93:10775-10778, 1996.

${ }^{140}$ Müller, M. F., and J. D. Ferry. Stress-relaxation in fine fibrin films-Comparison of films prepared with thrombin and ancrod. Biopolymers 23:2311-2323, 1984.

${ }^{141}$ Müsch, A. Microtubule organization and function in epithelial cells. Traffic 5:1-9, 2004.

${ }^{142}$ Nédélec, F., T. Surrey, and E. Karsenti. Self-organisation and forces in the microtubule cytoskeleton. Curr. Opin. Cell Biol. 15:118-124, 2003.

${ }^{143} \mathrm{Ng}$, C. P., C.-L. E. Helm, and M. A. Swartz. Interstitial flow differentially stimulates blood and lymphatic endothelial cell morphogenesis in vitro. Microvasc. Res. 68:258-264, 2004.

${ }^{144} \mathrm{Ng}$, C. P., B. Hinz, and M. A. Swartz. Interstitial flow movement is sufficient to induce a fibrotic response in fibroblasts in vitro. J. Cell Sci. 118:4731-4739, 2005.
${ }^{145} \mathrm{Ng}$, C. P., and M. A. Swartz. Fibroblast alignment under interstitial fluid flow using a novel 3D-tissue culture model. Am. J. Physiol. Heart Circ. Physiol. 284:H1771-H1777, 2003.

${ }^{146}$ Nusgens, B., C. Merrill, C. Lapiere, and E. Bell. Collagen biosynthesis by cells in a tissue equivalent matrix in vitro. Coll. Relat. Res. 4:351-364, 1984.

${ }^{147}$ O'Brien, L. E., K. Tang, E. S. Kats, A. Schutz-Geschwender, J. H. Lipschutz, and K. E. Mostov. ERK and MMPs sequentially regulate distinct stages of epithelial tubule development. Dev. Cell 7:21-32, 2004.

${ }^{148}$ Özerdem, B., and A. Tözeren. Physical response of collagen gels to tensile strain. J. Biomech. Eng. 117:397-401, 1995.

${ }^{149}$ Pagan, R., I. Martin, A. Alonso, M. Llobera, and S. Vilaro. Vimentin filaments follow the preexisting cytokeratin network during epithelial-mesenchymal transition of cultured neonatal rat hepatocytes. J. Cell Sci. 222:333-344, 1996.

${ }^{150}$ Pankov, R., and K. M. Yamada. Fibronectin at a glance. J. Cell Sci. 115:3861-3863, 2002.

${ }^{151}$ Pantaloni, D., C. Le Clainche, and M.-F. Carlier. Mechanism of actin-based motility. Science 292:1502-1506, 2001.

${ }^{152}$ Pedoe, D. Geometry, A Comprehensive Course. New York: Dover Publications, 1988.

${ }^{153}$ Pierce, J. A., and J. B. Hocott. Studies on the collagen and elastin content of the human lung. J. Clin. Invest. 39:8-14, 1960.

${ }^{154}$ Pinney, E., K. Liu, B. Sheeman, and J. Mansbridge. Human three-dimensional fibroblast cultures express angiogenic activity. J. Cell. Physiol. 183:74-82, 2000.

${ }^{155}$ Portet, S., O. Arino, J. Vassy, and D. Schoevaert. Organization of the cytokeratin network in an epithelial cell. J. Theor. Biol. 223:313-333, 2003

${ }^{156}$ Quinn, T. M., A. J. Grodzinsky, M. D. Buschmann, Y. J. Kim, and E. B. Hunziker. Mechanical compression alters proteoglycan deposition and matrix deformation around individual cells in cartilage explants. J. Cell Sci. 111:573-583, 1998.

${ }^{157}$ Ralphs, J. R., A. D. Waggett, and M. Benjamin. Actin stress fibres and cell-cell adhesion molecules in tendons: Organisation in vivo and response to mechanical loading of tendon cells in vitro. Matrix Biol. 21:67-74, 2002.

${ }^{158}$ Ramanujan, S., A. Pluen, T. D. McKee, E. B. Brown, Y. Boucher, and R. K. Jain. Diffusion and convection in collagen gels: Implications for transport in the tumor interstitium. Biophys. J. 83:1650-1660, 2002.

${ }^{159}$ Rigaut, J. P. Image cytometry. In: Image Analysis: Methods and Applications, edited by D. P. Häder, 2nd ed. Boca Raton, FL: CRC Press, 2001, pp. 185-207.

${ }^{160}$ Roeder, B. A., K. Kokini, J. E. Sturgis, J. P. Robinson, and S. L. Voytik-Harbin. Tensile mechanical properties of threedimensional type I collagen extracellular matrices with varied microstructure. J. Biomech. Eng. 124:214-222, 2002.

${ }^{161}$ Rojkind, M., and M. Mourelle. The liver as a bioecological system: Modifications during regeneration and repair. In: Collagen: Vol. 2: Biochemistry and Biomechanics, edited by M. E. Nimni. Boca Raton, FL: CRC Press, 1988, pp. 137-159.

${ }^{162}$ Ronfard, V., and Y. Barrandon. Migration of keratinocytes through tunnels of digested fibrin. Proc. Natl. Acad. Sci. U.S.A. 98:4504-4509, 2001.

${ }^{163}$ Rosenblatt, J., B. Devereux, and D. G. Wallace. Injectable collagen as a pH-sensitive hydrogel. Biomaterials 15:985-995, 1994.

${ }^{164}$ Rosenbloom, J., and W. R. Abrams. Elastin and the microfibrillar apparatus. In: Connective Tissue and Its Heritable Disorders: Molecular, Genetic and Medical Aspects, edited by P. M. Royce and B. Steinmann, 2nd ed. New York: Wiley-Liss, 2002, pp. 249-269. 
${ }^{165}$ Roska, F. J., and J. D. Ferry. Studies of fibrin film: 1 . Stress-relaxation and birefringence. Biopolymers 21:18111832, 1982.

${ }^{166}$ Rowley, J. A., G. Madlambayan, and D. J. Mooney. Alginate hydrogels as synthetic extracellular matrix materials. Biomaterials 20:45-53, 1999.

${ }^{167}$ Ryan, E. A., L. F. Mockros, J. W. Weisel, and L. Lorand. Structural origins of fibrin clot rheology. Biophys. J. 77:2813-2826, 1999.

${ }^{168}$ Sakiyama-Elbert, S. E., and J. A. Hubbell. Development of fibrin derivatives for controlled release of heparin-binding growth factors. J. Control. Release 65:389-402, 2000.

${ }^{169}$ Saltzman, W. M., M. L. Radomsky, K. J. Whaley, and R. A. Cone. Antibody diffusion in human cervical mucus. Biophys. J. 66:508-515, 1994.

${ }^{170}$ Sawada, Y., and M. P. Sheetz. Force transduction by Triton cytoskeletons. J. Cell Biol. 156:609-615, 2002.

${ }^{171}$ Sawhney, R. K., and J. Howard. Slow local movements of collagen fibers by fibroblasts drive the rapid global self-organization of collagen gels. J. Cell Biol. 157:1083-1091, 2002.

${ }^{172}$ Schmidt, C. E., A. F. Horwitz, D. A. Lauffenburger, and M. P. Sheetz. Integrin-cytoskeletal interactions in migrating fibroblasts are dynamic, asymmetric, and regulated. J. Cell Biol. 123:977-991, 1993.

${ }^{173}$ Schönherr, E., and H.-J. Hausser. Extracellular matrix and cytokines: A functional unit. Dev. Immunol. 7:89-101, 2000.

${ }^{174}$ Schor, S. L., T. D. Allen, and C. J. Harrison. Cell migration through three-dimensional gels of native collagen fibres: Collagenolytic activity is not required for the migration of two permanent cell lines. J. Cell Sci. 46:171-186, 1980.

${ }^{175}$ Schwartz, M. A. Integrin signaling revisited. Trends Cell Biol. 11:466-470, 2001.

${ }^{176}$ Scott, J. E. Extracellular matrix, supramolecular organisation and shape. J. Anat. 187:259-269, 1995.

${ }^{177}$ Serini, G., M.-L. Bochaton-Piallat, P. Ropraz, et al. The fibronectin domain ED-A is crucial for myofibroblastic phenotype induction by transforming growth factor- $\beta 1$. J. Cell Biol. 142:873-881, 1998.

${ }^{178}$ Shoeman, R. L., and P. Traub. Intermediate filament proteins. In: The Cytoskeleton: Structure and Assembly, edited by J. E. Hekseth and I. F. Pryme, Vol. 1. Greenwich: JAI Press, 1995, pp. 205-255.

${ }^{179}$ Shreiber, D. I., V. H. Barocas, and R. T. Tranquillo. Temporal variations in cell migration and traction during fibroblastmediated gel compaction. Biophys. J. 84:4102-4114, 2003.

${ }^{180}$ Silver, F. H., L. M. Siperko, and G. P. Seehra. Mechanobiology of force transduction in dermal tissue. Skin Res. Technol. 9:323, 2003.

${ }^{181}$ Simpson-Haidaris, P. J., and B. Rybarczyk. Tumors and fibrinogen: The role of fibrinogen as an extracellular matrix protein. Ann. N. Y. Acad. Sci. 936:406-425, 2001.

${ }^{182}$ Skalli, O., P. Ropraz, A. Trzeciak, G. Benzonana, D. Gillessen, and G. Gabbiani. A monoclonal antibody against a-smooth muscle actin: A new probe for smooth muscle differentiation. J. Cell Biol. 103:2787-2796, 1986.

${ }^{183}$ Spronk, H. M. H., J. W. P. Govers-Riemslag, and H. Ten Cate. The blood coagulation system as a molecular machine. Bioessays 25:1220-1228, 2003.

${ }^{184}$ Stephens, D. J., and V. J. Allan. Light microscopy techniques for live cell imaging. Science 300:82-86, 2003.

${ }^{185}$ Swartz, M. A. The physiology of the lymphatic system. $A d v$. Drug Delivery Rev. 50:3-20, 2001.

${ }^{186}$ Swartz, M. A. Signaling in morphogenesis: Transport cues in morphogenesis. Curr. Opin. Biotechnol. 14:547-550, 2003.
${ }^{187}$ Tada, S., and J. M. Tarbell. Interstitial flow through the internal elastic lamina affects shear stress on arterial smooth muscle cells. Am. J. Physiol. Heart Circ. Physiol. 278:H1589-H1597, 2000.

${ }^{188}$ Tada, S., and J. M. Tarbell. Internal elastic lamina affects the distribution of macromolecules in the arterial wall: A computational study. Am. J. Physiol. Heart Circ. Physiol. 287:H905H913, 2004.

${ }^{189}$ Takahashi, A., R. Kita, T. Shinozaki, K. Kubota, and M. Kaibara. Real-space observation of three-dimensional network structure of hydrated fibrin gel. Colloid Polym. Sci. 281:832838, 2003.

${ }^{190}$ Tamariz, E., and F. Grinnell. Modulation of fibroblast morphology and adhesion during collagen matrix remodeling. Mol. Biol. Cell. 13:3915-3929, 2002.

${ }^{191}$ Tan, J. L., J. Tien, D. M. Pirone, D. S. Gray, K. Bhadriraju, and C. S. Chen. Cells lying on a bed of microneedles: An approach to isolate mechanical force. Proc. Natl. Acad. Sci. U.S.A. 100:1484-1489, 2003.

${ }^{192}$ Tarbell, J. M. Mass transport in arteries and the localization of atherosclerosis. Ann. Rev. Biomed. Eng. 5:79-118, 2003.

${ }^{193}$ Thi, M. M., J. M. Tarbell, S. Weinbaum, and D. C. Spray. The role of the glycocalyx in reorganization of the actin cytoskeleton uner fluid shear stress: A "bumper-car" model. Proc. Natl. Acad. Sci. U.S.A. 101:16483-16488, 2004.

${ }^{194}$ Tomasek, J. J., G. Gabbiani, B. Hinz, C. Chaponnier, and R. A. Brown. Myofibroblasts and mechanoregulation of connective tissue remodeling. Nat. Rev. Mol. Cell Biol. 3:349-363, 2002.

${ }^{195}$ Toyoizumi, R., K. Mogi, and S. Takeuchi. Individual epiblast cells acquired invasiveness precedent to the primitive streak formation in the chick embryo. Zool. Sci. 14:313-320, 1997.

${ }^{196}$ Trächslin, J., M. Koch, and M. Chiquet. Rapid and reversible regulation of collagen XII expression by changes in tensile stress. Exp. Cell Res. 247:320-328, 1999.

${ }^{197}$ Tranquillo, R. T. Self-organization of tissue-equivalents: The nature and role of contact guidance. Biochem. Soc. Symp. 65:27-42, 1997.

${ }^{198}$ Tseng, Y., T. P. Kole, and D. Wirtz. Micromechanical mapping of live cells by multiple-particle-tracking microrheology. Biophys. J. 83:3162-3176, 2002.

${ }^{199}$ Tseng, Y. and D. Wirtz. Mechanics and multiple-particle tracking microheterogeneity of $\alpha$-actinin cross-linked actin filament networks. Biophys. J. 81: 1643-1656, 2001.

${ }^{200}$ Tuan, T. L., A. Song, S. Chang, S. Younai, and M. E. Nimni. In vitro fibroplasia: Matrix contraction, cell growth, and collagen production of fibroblasts cultured in fibrin gels. Exp. Cell Res. 223:127-134, 1996.

${ }^{201}$ von der Mark, K., and L. Sorokin. Adhesive glycoproteins. In: Connective Tissue and Its Heritable Disorders: Molecular, Genetic and Medical Aspects, edited by P. M. Royce and B. Steinmann, 2nd ed. New York: Wiley-Liss, 2002, pp. 293328.

${ }^{202}$ Vanni, S., B. C. Lagerholm, C. Otey, D. L. Taylor, and F. Lanni. Internet-based image analysis quantifies contractile behavior of individual fibroblasts inside model tissue. Biophys. J. 84:27152727, 2003.

${ }^{203}$ Viidik, A. Tendons and ligaments. In: Extracellular Matrix, Vol. 1: Tissue Function, edited by W. D. Comper, Vol. 1. Amsterdam: Harwood Academic Publishers GmbH, 1996, pp. 303-327.

${ }^{204}$ Visser, T., J. Oud, and G. Brakenhoff. Refractive index and axial distance measurements in 3-D microscopy. Optik 90:1719, 1992. 
${ }^{205}$ Voytik-Harbin, S. L., A. O. Brightman, B. Z. Waisner, J. P. Robinson, and C. H. Lamar. Small intestinal submucosa: A tissue-derived extracellular matrix that promotes tissue-specific growth and differentiation of cells in vitro. Tissue Eng. 4:157174, 1998.

${ }^{206}$ Voytik-Harbin, S. L., B. A. Roeder, J. E. Sturgis, K. Kokini, and J. P. Robinson. Simultaneous mechanical loading and confocal reflection microscopy for three-dimensional microbiomechanical analysis of biomaterials and tissue constructs. Microsc. Microanal. 9:74-85, 2003.

${ }^{207}$ Wang, Y.-L. Reorganization of actin filament bundles in living fibroblasts. J. Cell Biol. 99:1478-1485, 1984.

${ }^{208}$ Wang, N., J. P. Butler, and D. E. Ingber. Mechanotransduction across the cell surface and through the cytoskeleton. Science 260:1124-1127, 1993.

${ }^{209}$ Wang, H.-B., M. Dembo, S. K. Hanks, and Y.-L. Wang. Focal adhesion kinase is involved in mechanosensing during fibroblast migration. Proc. Natl. Acad. Sci. U.S.A. 98:11295-11300, 2001.

${ }^{210}$ Wang, N., and D. E. Ingber. Control of cytoskeletal mechanics by extracellular matrix, cell shape, and mechanical tension. Biophys. J. 66:2181-2189, 1994.

${ }^{211}$ Wang, N., E. Ostuni, G. M. Whitesides, and D. E. Ingber. Micropatterning tractional forces in living cells. Cell Motil. Cytoskeleton 52:97-106, 2002.

${ }^{212}$ Wang, S., and J. M. Tarbell. Effect of fluid flow on smooth muscle cells in a 3-dimensional collagen gel model. Arterioscler. Thromb. Vasc. Biol. 20:2220-2225, 2000.

${ }^{213}$ Waterman-Storer, C., D. Y. Duey, K. L. Weber, et al. Microtubules remodel actomyosin networks in Xenopus egg extracts via two mechanisms of f-actin transport. J. Cell Biol. 150:361376, 2000.

${ }^{214}$ Weber, K., E. Lazarides, R. D. Goldman, A. Vogel, and R. Pollack. Localization and distribution of actin fibers in normal, transformed and revertant cells. Cold Spring Harb. Symp. Quant. Biol. 39:363-369, 1974.
${ }^{215}$ Weinbaum, S., X. Zhang, Y. Han, H. Vink, and S. C. Cowin. Mechanotransduction and flow across the endothelial glycocalyx. Proc. Natl. Acad. Sci. U.S.A. 100:7988-7995, 2003.

${ }^{216}$ Williams, B. R., R. A. Gelman, D. C. Poppke, and K. A. Piez. Collagen fibril formation. J. Biol. Chem. 253:6578-6585, 1978.

${ }^{217}$ Winter, H. H., and M. Mours. Rheology of polymers near liquid-solid transitions. Adv. Polym. Sci. 134:165-234, 1997.

${ }^{218}$ Wolf, K., I. Mazo, H. Leung, et al. Compensation mechanism in tumor cell migration: Mesenchymal-amoeboid transition after blocking pericellular proteolysis. J. Cell Biol. 160:267-277, 2003.

${ }^{219}$ Wong, J. Y., A. Velasco, P. Rajagopalan, and Q. Pham. Directed movement of vascular smooth muscle cells on gradient-compliant hydrogels. Langmuir 19:1908-1913, 2003.

${ }^{220}$ Wood, G. C., and M. K. Keech. Formation of fibrils from collagen solutions: 1. Effect of experimental conditions-kinetic and electron-microscope studies. Biochem. J. 75:588-598, 1960.

${ }^{221} \mathrm{Xu}$, J., Y. Tseng, and D. Wirtz. Strain-hardening of actin filament networks- regulation by the dynamic cross-linking prottein $\alpha$-actinin. J. Biol. Chem. 275:35886-35892, 2000.

${ }^{222}$ Yang, S., J. Graham, J. W. Kahn, E. A. Schwartz, and M. E. Gerritsen. Functional roles for PECAM-1 (CD31) and VECadherin (CD144) in tube assembly and lumen formation in three-dimensional collagen gels. Am. J. Pathol. 155:887-895, 1999.

${ }^{223}$ Yeung, T., P. C. Georges, L. A. Flanagan, et al. Effects of substrate stiffness on cell morphology, cytoskeletal structure, and adhesion. Cell Motil. Cytoskeleton 60:24-34, 2005.

${ }^{224}$ Zimerman, B., T. Volberg, and B. Geiger. Early molecular events in the assembly of the focal adhesion-stress fiber complex during fibroblast spreading. Cell Motil. Cytoskeleton 58:143-159, 2004. 